\title{
ELECCIONES MUNICIPALES Y DERECHO AL VOTO DE LOS EXTRANJEROS NO COMUNITARIOS: ESTADO DE LA CUESTIÓN Y PROPUESTAS DE REFORMA
}

RAFAEL NARANJO DE LA CRUZ 
SUMARIO

1. INTRODUCCIÓN. 2. LA CLÁUSULA CONSTITUCIONAL DE RECIPROCIDAD. 2.1 La reciprocidad como requisito. 2.2 Hacia una nueva interpretación de la cláusula constitucional. 3. EL PROBLEMA DE LA FUENTE. 3.1 La superación del tratado internacional como norma de atribución del derecho. 3.2 Sobre la posibilidad de limitar el alcance del reconocimiento legal del derecho. 3.2.1 Exclusiones por razón de nacionalidad. 3.2.2 El criterio basado en el porcentaje de población extranjera residente. 3.2.3 Los casos particulares de Ceuta y Melilla. 4. LAS CONDICIONES DE EJERCICIO DEL DERECHO AL SUFRAGIO ACTIVO DE LOS EXTRANJEROS EN LAS ELECCIONES MUNICIPALES. 4.1 Límites a la actuación legislativa. 4.2 Análisis crítico del requisito de inscripción en el censo a instancia de parte. 


\title{
ELECCIONES MUNICIPALES Y DERECHO AL VOTO DE LOS EXTRANJEROS NO COMUNITARIOS: ESTADO DE LA CUESTIÓN Y PROPUESTAS DE REFORMA ${ }^{1}$
}

\author{
RAFAEL NARANJO DE LA CRUZ* \\ Profesor Titular de Derecho Constitucional \\ Universidad de Málaga
}

\section{INTRODUCCIÓN}

La previsión en el artículo $13.2 \mathrm{CE}^{2}$ de la posibilidad de extender, por tratado o ley, el derecho de sufragio activo a los extranjeros en las elecciones municipales situó nuestra regulación constitucional en este punto entre las más avanzadas de la época en la materia. Tan solo se incluía un requisito: que la norma que finalmente concretara tal atribución atendiera a criterios de reciprocidad.

1 Este trabajo forma parte del proyecto de investigación «Reforma electoral y derechos de participación de los extranjeros residentes en España: el derecho de sufragio en las elecciones generales, europeas, autonómicas y locales», financiado por el Ministerio de Economía y Competitividad (referencia DER2012-34411).

* Profesor titular de Derecho constitucional. Facultad de Derecho de la Universidad de Málaga, Campus de Teatinos 29071 Málaga. Correo electrónico: rnaranjo@uma.es.

2 Según el artículo 13.2 CE, «(s)olamente los españoles serán titulares de los derechos reconocidos en el artículo 23, salvo lo que, atendiendo a criterios de reciprocidad, pueda establecerse por tratado o ley para el derecho de sufragio activo y pasivo en las elecciones municipales». 
Esta cláusula, pensada originariamente para favorecer la situación de los emigrantes españoles en el extranjero ${ }^{3}$, se ha convertido con el tiempo, sin embargo, en un gran lastre. Interpretada por la doctrina y por los agentes políticos en términos de requisito de necesario cumplimiento para el reconocimiento del derecho, su efecto ha sido demoledor, al obligar a limitar su extensión únicamente a los nacionales de los pocos Estados que, a su vez, lo atribuían a los españoles. Así, hemos tenido que descartar todo instrumento normativo, de carácter convencional o legislativo, apto para atribuir con carácter general el derecho a todos los extranjeros y optar por la fórmula del tratado internacional bilateral, con unos resultados, como se verá, a todas luces pobres.

Si el desarrollo en términos cuantitativos del derecho ha sido escaso, tampoco se puede afirmar que su tratamiento normativo haya buscado facilitar al máximo el ejercicio del derecho por su titular extranjero. Al contrario, basándose en la idea de que se ha de conceder a la norma un amplio margen de actuación sobre un derecho que no es de obligado reconocimiento según la Constitución, los tratados ratificados por España en la materia han impuesto a su ejercicio un requisito, el de inscripción en el censo a instancia de parte para cada proceso electoral, de utilidad discutible y con un importante efecto desalentador sobre sus potenciales destinatarios.

Este trabajo pretende revisar los planteamientos hasta ahora solo someramente esbozados, con el objetivo reconocido de facilitar la mayor expansión posible del derecho al voto de los extranjeros no comunitarios en las elecciones municipales ${ }^{4}$. Nuestra premisa es que los extranjeros que residen de manera legal y estable en nuestro país deben poder disfrutar del derecho al voto, al menos en los procesos electorales mencionados, como exigencia básica del principio democrático y en aras de su mayor integración en la sociedad en la que convive. Expondremos para ello, en primer lugar, una nueva interpretación de la referencia constitucional a la reciprocidad que la hace compatible con este objetivo. Veremos a continuación que

${ }^{3}$ Una visión favorable del requisito en estos términos, en Pérez Vera, E. y Abarca Junco, P. (1997). «Artículo 13.2», en Alzaga Villaamil, Ó. (coord.), Comentarios a la Constitución Española de 1978, Tomo II, Madrid, Cortes Generales /EDERSA, p. 206.

${ }^{4}$ Quedan, por tanto, fuera de las consideraciones de este trabajo los ciudadanos de la Unión Europea y los procesos electorales distintos de las elecciones municipales. En relación con el voto de los ciudadanos de la Unión Europea en las elecciones municipales, véase NAVAS SÁNCHEZ, M. ${ }^{a}$ del M. (2016). «El derecho al voto de los ciudadanos de la Unión Europea en las elecciones municipales. De la ciudadanía de la Unión a las condiciones de ejercicio del derecho», Revista Europea de Derechos Fundamentales, núm. 27, pp. 229-256. Una visión comparada en el ámbito de la Unión Europea, en SÁnChEZ-Molina, P. (2016), La extensión del derecho de sufragio de los extranjeros residentes en los Estados miembros de la Unión Europea», Revista Europea de Derechos Fundamentales, núm. 27 , pp. 365 y ss. 
esta comprensión de la reciprocidad abre las puertas a una regulación del derecho por ley que, de manera general, lo atribuya a todos los extranjeros con independencia de su procedencia, reduciendo así al mínimo constitucionalmente necesario las desigualdades entre ellos. Por último, será necesario adentrarse en el estudio de los márgenes en los que dicha ley se debe mover a la hora de regular las condiciones de ejercicio del derecho por los extranjeros.

\section{LA CLÁUSULA CONSTITUCIONAL DE RECIPROCIDAD}

\subsection{La reciprocidad como requisito}

Como es sabido, el artículo 13.2 CE dispone que la atribución del derecho de sufragio activo o pasivo al extranjero en las elecciones municipales se haga «atendiendo a criterios de reciprocidad». Este requisito tiene como destinatario a la ley o al tratado internacional que el precepto constitucional erige como auténtica norma de atribución. Sin esta, pues, ningún extranjero es titular del derecho al voto en las elecciones municipales 5 .

Generalizada la concepción de la reciprocidad como conditio sine qua non para la atribución normativa del derecho a los extranjeros, la doctrina centró su atención en el alcance que debía darse a esta exigencia. Al respecto, si bien en algún caso se apuntó a la necesidad de equivalencia entre los elementos principales del sistema electoral español y el del país correspondiente ${ }^{6}$, esta tesis quedó descartada ante la evidencia de que con ella la previsión del artículo 13.2 CE quedaría prácticamente privada de contenido ${ }^{7}$. Así, se generalizó una interpretación «suave» de la reciprocidad, que la agotaba, básicamente, en tres elementos: la necesidad de reconocimiento a los españoles de su derecho al sufragio en sus

5 Sobre la insuficiencia de la existencia de una reciprocidad material para el reconocimiento del derecho, Moya, D. (2010). «Regulación del derecho de sufragio de los extranjeros en España y los mecanismos alternativos de participación política», en MOYA MALAPEIRA, D. y VIÑAS Ferrer, A. (eds.), Sufragio y participación política de los extranjeros extracomunitarios en Europa, Barcelona, Fundació Carles Pi i Sunyer, p. 468. En contra, Santolaya, P. (2007). «Nacionalidad, extranjería y derecho de sufragio», en Santolaya Machetti, P. y Revenga Sánchez, M., Nacionalidad, extranjería y derecho de sufragio, Madrid, Centro de Estudios Políticos y Constitucionales, pp. 44-45.

${ }^{6}$ En este sentido, Ferrer Peña, R. M. ${ }^{a}$ (1989). Los derechos de los extranjeros en España, Madrid, Tecnos, p. 78.

7 Santolaya Machetti, P. (2009). «El derecho de sufragio de los extranjeros», en VV. AA. El informe del Consejo de Estado sobre la reforma electoral. Texto del informe y debates académicos, Madrid, Consejo de Estado/CEPC, p. 516. 
respectivas elecciones municipales, el carácter democrático de dichos procesos electorales y la ausencia de condiciones de ejercicio o requisitos exorbitantes o discriminatorios ${ }^{8}$.

La Ley, por su parte, adoptó una concepción de la exigencia de reciprocidad en su contenido mínimo. En este sentido, el artículo 176.1 de la Ley Orgánica Reguladora del Régimen Electoral General (en adelante, LOREG) hace referencia a «los residentes extranjeros en España cuyos respectivos países permitan el voto a los españoles en dichas elecciones». Parece, pues, que el cumplimiento de dicha condición es suficiente para poder reconocer el derecho al sufragio en las elecciones municipales a los extranjeros de una determinada nacionalidad, sin necesidad de profundizar en consideraciones de otro tipo ${ }^{9}$. La práctica convencional desarrollada por España en la materia se ha mantenido en los mismos términos mínimos, en la medida en que en todos los tratados internacionales ratificados se recoge la posibilidad de modificar las condiciones de ejercicio previstas «siempre y cuando el derecho de voto reconocido en (el) Acuerdo sea mantenido» ${ }^{10}$.

Aun desde esta concepción «minimalista» de la reciprocidad, su interpretación como condición inexcusable para el reconocimiento del derecho al voto a los extranjeros en el ámbito municipal ha lastrado el desarrollo y la expansión de la previsión constitucional ${ }^{11}$. En este sentido, la necesidad de satisfacer el requisito de reciprocidad, entendido en los términos expuestos, ha impedido en un buen número de supuestos la atribución a los extranjeros de este derecho. Así ha ocurrido cuando procedían de países en los que los españoles tampoco son titulares del citado derecho o de Estados no democráticos, en los que sencillamente no se lleva

\footnotetext{
8 Santolaya, Nacionalidad..., cit., 43. Partidarios de dotar de un alcance mínimo al criterio de reciprocidad, SAntolaya Machetti, El derecho de sufragio..., cit., 515; PÉREZ Alberdi, M. ${ }^{a}$ R. (2013). El derecho fundamental a participar en los asuntos públicos, Madrid, Congreso de los Diputados, pp. 99-100. Dentro de esta línea, Moya hace hincapié en la exigencia de que los comicios locales puedan ser calificados como democráticos, de acuerdo con los estándares internacionalmente aceptados (op. cit., p. 469, especialmente nota 9).

9 En los mismos términos, véase el informe elaborado por el Consejo de Estado sobre la reforma electoral (en adelante, citado como el «informe» o el «informe del Consejo de Estado»), citado por VV. AA. (2009). El informe del Consejo de Estado sobre la reforma electoral. Texto del informe y debates académicos, Madrid, Consejo de Estado/CEPC, p. 27.

10 Sobre la versión «debilitada» que del requisito de reciprocidad se deriva de los tratados ratificados, Santolaya Machetti, P. (2011). «Los Acuerdos sobre voto en las elecciones municipales de la IX Legislatura», en Matia Portilla, F. J. (dir.), Pluralidad de ciudadanías, nuevos derechos y participación democrática, Madrid, Centro de Estudios Políticos y Constitucionales, p. 27.

11 Por todos, Revenga Sánchez, M. (2007). «El reto de la normalización del inmigrante», en Santolaya Machetti, P. y Revenga Sánchez, M., Nacionalidad, extranjería y derecho de sufragio, Madrid, Centro de Estudios Políticos y Constitucionales, p. 88.
} 
a cabo ningún proceso electoral o no se hace con las garantías aquí existentes ${ }^{12}$. Desde este punto de vista, se ha entendido que falta reciprocidad también en el caso de los Estados que, aun reconociendo el derecho a los españoles, lo someten a condiciones extravagantes o discriminatorias, de las que se deriva la exclusión de personas que según nuestro ordenamiento disfrutarían del derecho ${ }^{13}$. Más dudas plantea, sin embargo, la afirmación de que la ausencia en un país de unos entes equivalentes a nuestros municipios impide por sí sola la existencia de reciprocidad. En tales casos bastaría, creemos, la atribución a los españoles del derecho al voto en sus elecciones centrales o regionales para dar la condición por satisfecha ${ }^{14}$.

El requisito de reciprocidad ha suscitado también problemas en los supuestos de Estados compuestos en los que la competencia normativa sobre el reconocimiento del derecho al voto de los extranjeros en las elecciones municipales no

12 Sobre este asunto, SAntolaya, Nacionalidad..., cit., p. 24: El derecho de sufragio..., cit., pp. 515-516; AJA, E. y MOYA, D. (2009). El derecho de sufragio de los extranjeros residentes (disponible en: http://idpbarcelona.net/docs/blog/der_sufragio.pdf; última visita 12/06/2017), p. 18; ORTEGA Giménez, A. (2011). «El derecho al voto de los ciudadanos extracomunitarios en las próximas elecciones municipales españolas de 2011», Madrid, Fundación Alternativas Ortega Giménez, p. 37; Santolaya Machetti, Los Acuerdos..., cit., p. 21; Ortega Jiménez, A., López Álvarez, A. y CANo Esquibel, M. J. (2011). «A vueltas con la integración del inmigrante: la extensión del derecho al voto de los ciudadanos extranjeros en España», comunicación presentada a «Los actores de las políticas sociales en contextos de transformación. III Congreso anual de la REPS» (http://www. unavarra.es/digitalAssets/149/149682_1000003.1_Ortega_DerechoVotoExtranjeros.pdf; última visita: 14/03/2016); GARCía VÁZQUEZ, S. (2007). El estatuto jurídico-constitucional del extranjero en España, Valencia, Tirant lo Blanch, p. 249; AJA, E. (2012). Inmigración y democracia, Madrid, Alianza Editorial, pp. 421-422; Revenga SÁnCHEz, op. cit., p. 88. Sin embargo, el Consejo de Estado concluye en su informe que «no se exige que se trate de regímenes democráticos con "fair and free elections"» (op. cit., p. 27). En contra también de la interpretación que excluye a los nacionales de países no democráticos, LASAgABASTER HerrarTe, I. (2009). «Reciprocidad y derechos fundamentales: en especial el derecho de voto de los extranjeros», Revista Vasca de Administración Pública, núm. 85, pp. 77-78. Sobre las dificultades a las que se enfrenta esta visión alternativa, CARrASCO DuráN, M. (2010). «El derecho de voto de los extranjeros en las elecciones municipales. Nuevas realidades», Cuadernos de Derecho Local. Fundación Democracia y Gobierno Local, febrero, I, p. 155.

13 Santolaya, El derecho de sufragio..., cit., p. 516. Al respecto, Santolaya califica de «exigencia constitucionalmente francamente dudosa» la relativa a «constituir familia», prevista en el artículo 78 de la Constitución de Uruguay (Nacionalidad..., cit., p. 61). En un sentido similar, IbáÑez Macías, A. (2009). El derecho de sufragio de los extranjeros, Madrid, Instituto de Derechos Humanos Bartolomé de las Casas Universidad Carlos II de Madrid/Dykinson, p. 60; SantolaYA Machetti, Los Acuerdos..., cit., p. 28; Ortega Giménez-López Álvarez-Cano Esquibel, op. cit., p. 6.

14 En contra, Aja-Moya, op. cit., p. 18. Para Santolaya Machetti, sin embargo, cabe afirmar la reciprocidad aunque las elecciones no correspondan exactamente desde el punto de vista territorial con la de nuestro municipios (Los Acuerdos..., cit., p. 22).

N. ${ }^{\circ} 100$, septiembre-diciembre 2017, págs. 81-122 
es ostentada por los poderes centrales del Estado ${ }^{15}$. Este ha sido el caso de Argentina, cuyo acuerdo no ha superado el trámite parlamentario a la vista de que son las provincias las competentes en la materia y no en todas ellas se reconocía el correspondiente derecho a los españoles ${ }^{16}$.

Parte de la doctrina ha intentado paliar las dificultades insuperables que para el reconocimiento del derecho de sufragio a los extranjeros se suscitan a raíz de la interpretación dada a la cláusula constitucional de reciprocidad mediante la propuesta, como alternativa, del expediente de adquisición de la nacionalidad española, de cara al logro de la mayor difusión posible del derecho entre los residentes en España ${ }^{17}$. Sin embargo, no puede perderse de vista, por un lado, las duras condiciones a las que queda sujeta esta opción en buena parte de los casos: principalmente un período de residencia muy elevado ${ }^{18}$ [10 años, según el artículo 22.1 del Código Civil (en adelante, CC)] y la renuncia a su anterior nacionalidad, salvo en el caso de nacionales de origen de países iberoamericanos, Andorra, Filipinas, Guinea Ecuatorial o Portugal o de sefardíes [art. 23.b) CC]. Sea como fuere, la vía de la adquisición de la nacionalidad es una falsa solución para el problema que nos ocupa, ya que únicamente disimula la cuestión de fondo, relativa a la participación política de los extranjeros, mediante el expediente de reducir su número ${ }^{19}$, dejando por tanto sin afrontar la situación de aquellos extranjeros residentes que no pueden, o no quieren, cumplir las exigencias legales.

Los efectos excluyentes de esta concepción de la cláusula de reciprocidad han conducido al derecho al sufragio de los extranjeros en las elecciones locales a un

15 Propone para estos casos optar por la solución más favorable al reconocimiento del derecho el Consejo de Estado en su informe (op. cit., p. 61).

16 Sobre esta cuestión véanse SAntolaya, Nacionalidad..., cit., pp. 60-61, MarTíneZPujalte, A. L. (2010). Los sistemas electorales españoles: evaluación y propuestas de mejora, Madrid, Dykinson, p. 126; Santolaya, P. y Díaz Crego, M. ${ }^{\text {a }}$ (2008). El sufragio de los extranjeros. Un estudio de Derecho comparado, Madrid, Centro de Estudios Políticos y Constitucionales, pp. 108 y ss.; Santolaya Machetti, Los Acuerdos..., cit., p. 29 o Carrasco Durán, op. cit., p. 159.

17 MOYA, op. cit., p. 496; SAgARRA Trías, E. (2002). La legislación sobre extranjería e inmigración: una lectura. Los derechos fundamentales de los extranjeros en España, Barcelona, Universitat de Barcelona, p. 342.

18 Apunta este argumento Santolaya, Nacionalidad..., cit., p. 72.

19 Como dice Santolaya Machetti, «de lo que se trata es de aumentar los derechos de los extranjeros y no, de forma un punto artificial, el número de los españoles (...)» (El derecho..., cit., p. 521). En contra de limitar la solución a la adquisición de la nacionalidad, en términos generales, Presno Linera, M. A. (2016), «El sufragio de los extranjeros residentes en las elecciones generales como exigencia de una ciudadanía democrática, Revista Europea de Derechos Fundamentales, núm. 27, p. 279. 
callejón sin salida ${ }^{20}$. Se considera que las posibilidades actuales de seguir ampliando el círculo de destinatarios del derecho son prácticamente nulas, a la vista del contexto internacional ${ }^{21}$, y se da por hecho que una ley que reconociera con carácter general el derecho a todos los extranjeros, cualquiera que fuera su país de procedencia, sería inconstitucional ${ }^{22}$. El efecto discriminatorio producido entre los extranjeros en función de su nacionalidad es evidente ${ }^{23}$, en perjuicio, en ocasiones, de los procedentes de países con gran representación en nuestro territorio, como China o Marruecos ${ }^{24}$.

Ante esta situación conviene preguntarse por el sentido y la finalidad que en la actualidad tiene en nuestro ordenamiento el reconocimiento del derecho al voto al extranjero en las elecciones municipales. La norma constitucional responde, entre otras consideraciones, a una exigencia básica del carácter democrático de nuestro Estado. Este obliga, a modo de principio, a tener en cuenta, para constituir los poderes públicos que han de aprobar las normas de nuestro ordenamiento, la voluntad de todos aquellos que pueden quedar previsiblemente sujetos al mismo de manera estable. El efecto expansivo que para el derecho deriva del principio democrático queda, sin embargo, definitivamente condicionado por otra lógica contrapuesta, introducida por el constituyente a la vista de las específicas circunstancias sociales de la época. Así, el criterio de reciprocidad, ajeno a la dogmática propia de los derechos fundamentales ${ }^{25}$, condiciona el

${ }^{20}$ Con el fin de evitar los efectos perniciosos del requisito constitucional, se ha llegado a proponer «interpretar de forma laxa la exigencia de reciprocidad del artículo 13.2: en el sentido de que no sería una reciprocidad absoluta o de resultado, sino que la exigencia del 13.2 se cumpliría con un mero compromiso de reciprocidad genérica, casi de intención, de las partes», VACAS FERNÁNDEZ, F. (2011). El reconocimiento del derecho al sufragio de los extranjeros en España: un análisis desde el Derecho Internacional, Madrid, Instituto de Derechos Humanos Bartolomé de las Casas, Universidad Carlos III de Madrid, Dykinson, p. 87 (cursiva también en el original). En contra, OrTEGA GIMÉNEZ, op. cit., p. 38.

21 Santolaya Machetti, Los Acuerdos..., cit., pp. 31-32; Vacas Fernández, op. cit., pp. $85-86$.

22 Por todos, Aja, E. y Díez Bueso, L. (2000). «La participación política de los inmigrantes», Revista Bimensual de Pensamiento Social. La factoría 10, p. 6 (obtenido en http://www.revistalafactoria.eu/articulo.php?id=141; última visita: 15/05/2014); GARCía SORIANO, M. ${ }^{a}$ V. (2007). «Sobre la viabilidad de la participación política de los extranjeros en las elecciones municipales», Cuadernos Constitucionales de la Cátedra Fadrique Furió Ceriol, núms. 60-61, pp. 264.

23 Al respecto, Aja-Díez Bueso, op. cit., p. 2; Ortega Giménez, op. cit., p. 37; VaCAs FERNÁNDEZ, op. cit., p. 80.

24 Entre otros, Ortega Giménez-López Álvarez-Cano Esquibel, op. cit., p. 6 y Ortega GiménEZ, op. cit., p. 30;

25 Sobre el carácter extraño del criterio de reciprocidad a la dogmática de los derechos fundamentales, Rodríguez-Drincourt Álvarez, J. (1997). Los derechos políticos de los extranjeros, 
alcance del derecho a la búsqueda de un resultado que nada tiene que ver con la situación del extranjero en nuestro país: mejorar la integración de nuestros nacionales emigrantes en sus países receptores. Es esta tensión interna apreciable en el precepto constitucional la causa última de su escasa virtualidad práctica ${ }^{26}$.

Lo cierto es que ni las corrientes migratorias responden en la actualidad a los mismos patrones de la época constituyente ${ }^{27}$, ni el criterio de reciprocidad ha mostrado una especial utilidad para mejorar la integración social y política del español emigrante en sus respectivos países receptores ${ }^{28}$. Una revisión de la intención del constituyente en la época actual arroja serias dudas sobre la conveniencia de mantener dicho requisito en el texto constitucional, de ahí que se haya hecho en ocasiones referencia a la necesidad de una reforma del artículo 13.2 CE en este punto.

En este sentido, se ha propuesto una modificación de mínimos, basada en la mera supresión de la referencia a la reciprocidad. El artículo 13.2 CE pasaría a decir lo siguiente: «(s)olamente los españoles serán titulares de los derechos reconocidos en el artículo 23, salvo lo que pueda establecerse por tratado o ley para el derecho de sufragio activo y pasivo en las elecciones municipales» ${ }^{29}$.

Madrid, Universidad de Las Palmas de Gran Canaria/Civitas, p. 337; DE Asís RoIG, R. (2005). «La participación política de los inmigrantes. Hacia una nueva generalización de los derechos», en VV. AA., Derechos fundamentales, valores y multiculturalismo, Madrid, Dykinson, p. 211; SANTOLAYA, Nacionalidad..., cit., p. 38; AJA, op. cit., p. 421-422; SANTOLAYA y Díaz Crego, op. cit., p. 15; Santolaya Machetti, Los Acuerdos..., cit., p. 21; Lasagabaster Herrarte, op. cit., p. 64; Carrasco Durán, op. cit., p. 162.

26 Como afirma Rodríguez-Drincourt Álvarez, «la atribución de derechos de participación política a extranjeros es sobre todo un problema de derecho público interno y (...) su internacionalización, por el criterio de reciprocidad, es ineficaz y disfuncional al problema de fondo al que parcialmente intenta dar solución el artículo 13.2 de la CE de 1978 con la participación política limitada de los extranjeros en España» (op. cit., p. 338). En términos parecidos reflejan esta tensión GARCÍA VÁZQUEZ, para quien la disfuncionalidad producida «no resultará democráticamente soportable cuando comencemos a tener en España extranjeros de «segunda generación», que hayan nacido en nuestro país y lleven toda su vida viviendo aquí» (op. cit., p. 248).

27 Al respecto, entre otros, AJA-MoYA, op. cit., p. 12; IBÁÑEz Macías, El derecho de sufragio..., cit., pp. 65-66; Santolaya Machetti, Los Acuerdos..., cit., p. 21; Vidal Fueyo, M. ${ }^{a}$ del C. (2009). «La conveniencia de ampliar la reforma constitucional más allá de los cuatro bloques de materias propuestos por el Gobierno», en Vera Santos, J. M. y Díaz Revorio, F. J. (coords.), La reforma estatutaria y constitucional, Madrid, La Ley, p. 786.

${ }_{28}$ En este sentido, el informe del Consejo de Estado, op. cit., p. 49. De hecho, VACAS FerNÁNDEZ pone de manifiesto cómo, a diferencia de lo que ocurrió en el caso de Noruega, este objetivo no desempeñó papel alguno en la ratificación de los tratados más recientes (op. cit., p. 68).

29 Propone esta redacción AJA (op cit., p. 425). Para PÉrez AlBERd, «(h)abría sido más atinado que la Constitución hubiese definido éste también como un derecho de configuración legal sin más requisitos, dejando al legislador o al acuerdo internacional la decisión de extender los derechos de sufragio a los extranjeros de las distintas nacionalidades» (op. cit., p. 100). 
Esta propuesta, sin embargo, no permite alcanzar un resultado óptimo desde el punto de vista del principio democrático. En efecto, una reforma con este contenido seguiría haciendo necesaria la intervención de la ley o del tratado internacional para el reconocimiento del derecho a los extranjeros ${ }^{30}$. Permitiría entonces que la situación continuara en el modo en el que está en la actualidad, a la espera de una mayoría parlamentaria con voluntad política para adoptar la decisión de extender el derecho a todos los extranjeros. Tampoco se puede ignorar que tal decisión sería igualmente revocable por una eventual mayoría en sentido contrario.

En el contexto de esta propuesta tiene sentido plantearse si, una vez suprimida la referencia constitucional a la reciprocidad, esta podría no obstante ser utilizada por el legislador de desarrollo como criterio para extender el derecho ${ }^{31}$. A nuestro juicio, una vez suprimida la referencia a la reciprocidad, su uso por el legislador debería considerarse vedado. Como hemos visto, se trata de un criterio ajeno a la dogmática tradicional de los derechos fundamentales. Sería impensable que esta misma cuestión pudiera llegar a ser planteada en relación con cualquier otro derecho fundamental, lo que apunta a su exclusión también en relación con el derecho al voto.

Por otra parte, en la medida en que cualquier norma de este tipo actuaría a modo de condición para el ejercicio del derecho, sería necesario, de acuerdo con la jurisprudencia constitucional en la materia, que su uso estuviera respaldado por la necesidad de proteger o garantizar cualquier otro bien o derecho constitucionalmente reconocido. Más allá de que exista un legítimo interés en la protección de los españoles en el extranjero, no resulta fácil encontrar acomodo de dicho objetivo en nuestra Constitución. El artículo 42 CE se muestra en su literalidad insuficiente para ello, toda vez que se refiere exclusivamente a los derechos económicos y sociales, expresión en la que no encaja el derecho al sufragio.

Un mayor avance supondría, sin duda, la atribución directa de la titularidad del derecho al sufragio en las elecciones municipales a los extranjeros. En este caso, el texto del artículo 13.2 CE podría quedar como sigue: «(s)olamente los españoles serán titulares de los derechos reconocidos en el artículo 23, salvo en el caso del derecho de sufragio activo y pasivo en las elecciones municipales». De esta manera quedaría fuera de toda duda la titularidad por los extranjeros del derecho. La referen-

30 AJA propone incluso una supresión de la remisión al tratado, en tanto que superflua, «salvo que se prefiera conservar como objetivo de política internacional» (op. cit., p. 425).

31 En este sentido, Santolaya Machetti, El derecho..., cit., p. 522. Para Lasagabaster Herrarte, «nada impediría establecer ese principio en la normativa ordinaria si se estimase necesario o si lo fuese en relación con algunos Estados» (op. cit., p. 71). 
cia expresa a la ley o los tratados no sería en realidad necesaria, toda vez que, una vez reconocida la titularidad del derecho, la regulación de las condiciones de su ejercicio quedarían sujetas a las normas constitucionales generales en materia de fuentes.

En definitiva, lo que aquí se sostiene es que una futura reforma de la Constitución debe evitar cualquier redacción del artículo 13.2 CE que deje en manos de la intervención posterior de una ley o tratado la atribución del derecho al extranjero. Se ha de utilizar, pues, una fórmula que lo reconozca de manera directa, cerrando así de una vez por todas esta cuestión.

\subsection{Hacia una nueva interpretación de la cláusula constitucional}

Como hemos visto, la mejor opción de cara a un cambio en el tratamiento jurídico del derecho al voto del extranjero en las elecciones municipales pasa, sin duda, por una reforma de la Constitución en este punto que suprima la actual referencia a la reciprocidad, sacando así la cuestión del debate jurídico y político ${ }^{32}$. Sin embargo, a diferencia de lo que se sostiene de manera prácticamente unánime por la doctrina ${ }^{33}$, no creemos que la reforma constitucional sea la única salida posible al punto muerto al que se ha llegado en la materia objeto de nuestro estudio.

Las posibilidades interpretativas del artículo 13.2 CE no han sido exploradas aún en su totalidad. Como destacamos con anterioridad, la doctrina se ha centrado únicamente en el significado y alcance que se podía otorgar al término «reciprocidad», obviando el contexto en el que se sitúa la referencia al mismo, dentro del propio precepto. Este permite al tratado o a la ley reconocer el derecho de sufragio activo - y pasivo- a los extranjeros en las elecciones municipales «atendiendo a criterios de reciprocidad». A nuestro juicio, lo que la doctrina y nuestros poderes públicos han hecho de manera unánime es una interpretación innecesariamente reductora de lo dispuesto en el texto constitucional ${ }^{34}$. Cierta-

32 Partidarios de una reforma constitucional, entre otros muchos, MoyA, op. cit., p. 475. Limitamos nuestra exposición en este punto a una eventual reforma constitucional que afectara al derecho al sufragio de los extranjeros en las elecciones municipales. Aunque creemos que el principio democrático obligará, con el tiempo, a reconsiderar igualmente la situación respecto de las elecciones autonómicas e, incluso, generales, estas últimas se quedan fuera de nuestro objeto de estudio.

33 Así, por ejemplo, expresamente, AJA, quien apunta a que la norma constitucional no puede adaptarse a la nueva situación social ni por vía de la legislación ni por vía de la interpretación (op. cit., p. 423).

34 La imposibilidad de reconocer el derecho a los extranjeros a falta de reciprocidad es una constante apreciable, de forma expresa o implícita, en nuestra doctrina. De manera expresa, entre otros, Presno Linera, M. A. (2003). El derecho al voto, Madrid, Tecnos, p. 166. En contra también 
mente, se atiende a criterios de reciprocidad cuando se niega el derecho a los extranjeros procedentes de países en los que este no es reconocido a nuestros nacionales. Lo que no está tan claro es que no exista otro modo de atender a dicho criterio $^{35}$. Para desarrollar nuestra argumentación nos valdremos de una línea argumental apuntada en su momento por el Consejo de Estado en su Informe sobre las propuestas de modificación del régimen electoral general de $2009^{36}$.

Allí, el órgano consultivo se cuestiona

«si el legislador español está determinado - y no solo condicionado- por el régimen de reciprocidad, en el sentido de si está o no obligado ex Constitutione a denegar a los residentes extranjeros el derecho de sufragio por el hecho de que se les deniegue a los españoles en el Estado extranjero de que se trate. En todo caso, la ley española debe tener en cuenta o tomar en consideración («atender») el régimen de reconocimiento o denegación del derecho de sufragio a los españoles en ese Estado extranjero. Es esto lo que la Constitución exige y no la sujeción del legislador a una estricta aplicación del principio de reciprocidad; así se desprende de la literalidad del artículo 13.2 que no exige la aplicación de tal principio, sino que se atienda a criterios de reciprocidad ${ }^{37}$.

El Consejo de Estado se plantea de este modo la existencia de una alternativa a la exigencia de que cada supuesto de reconocimiento del derecho responda al cumplimiento del principio de reciprocidad. A su juicio,

«cabrían otros posibles desarrollos si se parte de que el tratado o la ley pueden establecer una regulación que incorpore salvedades a la reserva del derecho de sufragio a los españoles, y que es esa regulación general (y no cada reconocimiento) la que ha de atender a criterios de reciprocidad (sin perjuicio de que éstos pudieran combinarse con otros diversos). En suma, los criterios de reciprocidad se predicarían de la «regulación» que estableciera las salvedades y no de cada una de ellas» ${ }^{38}$.

de cualquier interpretación del texto constitucional que permita reconocer el derecho al voto en ausencia de reciprocidad, Martínez-Pujalte, op. cit., p. 124; Moreno Blesa, L. (2001). «Artículo 6. Participación política», en Campo Cabal, J. M. (coord.), Comentarios a la Ley de Extranjería (Ley Orgánica 4/2000 reformada por la Ley Orgánica 8/2000), Madrid, Civitas, p. 74.

35 Este argumento puede verse en NARANjo DE LA CruZ, R. (2016). «El derecho al voto de los extranjeros no comunitarios en las elecciones municipales: reciprocidad, ciudadanía y condiciones de ejercicio del derecho», Revista Europea de Derechos Fundamentales, núm. 27, pp. 337 y ss.

${ }^{36}$ En contra de esta interpretación propuesta por el Consejo de Estado, Martínez-Pujalte, op. cit., p. 124 .

37 Informe, pp. 55-56.

${ }^{38}$ Ibidem, p. 57. 
El órgano consultivo sostuvo entonces que la interpretación clásica de la exigencia de reciprocidad «tiene la ventaja de su más nítido encaje constitucional» y es coherente con la llamada realizada por el artículo 13.2 CE a los tratados, mientras que, por el contrario, limita el margen de maniobra del legislador español, que se ve condicionado por la decisión que al respecto adopte el Estado extranjero, de forma que «la mención a la ley parece apuntar en una dirección distinta, abriendo posibilidades diferentes» ${ }^{39}$.

Por último, el Consejo de Estado afirmó que una interpretación sistemática del artículo 13.2 CE con el artículo $140 \mathrm{CE}$

«puede apoyar que la atención a criterios de reciprocidad a que se refiere el artículo 13.2 no se identifique con una rígida aplicación del principio de reciprocidad para el reconocimiento del derecho de sufragio (activo) a los extranjeros (a quienes, como regla, se les reconoce en el artículo 140 a través del concepto de vecino), sino más bien como una exigencia de que aquellos criterios sean tenidos en cuenta, en una u otra medida, al regular el derecho de sufragio de los extranjeros» ${ }^{40}$.

Ciertamente, el propio Consejo de Estado no se atrevió a ser totalmente congruente con su argumentación, que quedó, por así decir, inconclusa ${ }^{41}$. En algunos de sus fragmentos el órgano consultivo limita el alcance de sus consideraciones a la conclusión de que el requisito de reciprocidad no exige que el reconocimiento del derecho al extranjero se realice en los mismos términos en los que el derecho es atribuido a los españoles en el país en cuestión ${ }^{42}$. Para nosotros, sin embargo, un desarrollo de las mismas premisas mantenidas en el informe podría llevar a otorgar cobertura al reconocimiento del derecho, incluso, en aquellos supuestos en los que falta una reciprocidad entre países.

Si la norma de desarrollo «atiende» al criterio de reciprocidad por el mero hecho de tenerlo en consideración, no se puede negar que una regulación que tuviera en cuenta la existencia o falta de reciprocidad, no para el reconocimiento

39 Ibidem. En contra de la posición del Consejo, se ha afirmado que «no se trata de la «vía más clara», sino de la única constitucionalmente posible» (PreSNO LinERA, M. A. (2009). «El voto de los extranjeros en España y el voto de los españoles residentes en el extranjero. A propósito del informe del Consejo de Estado sobre las propuestas de modificación del régimen electoral general», Revista Española de Derecho Constitucional, núm. 87, p. 201).

40 Informe, op. cit., p. 58.

41 Crítico con la ambigüedad de la posición del Consejo de Estado en su informe, DELGadoIribarren García-CAMpero, M. (2014). «Artículo 176», en, del mismo autor (coord.), Comentarios a la Ley Orgánica del Régimen Electoral General y a la Ley Orgánica de Referéndum, Madrid, La Ley, pp. 1472-1473.

42 Informe, op. cit., p. 56. 
mismo del derecho, sino para la configuración de su régimen jurídico daría satisfacción a la cláusula constitucional. Más concretamente, lo que aquí se defiende es que la atribución por ley del derecho al voto en las elecciones municipales a todos los extranjeros es conforme con la Constitución, siempre que la existencia de reciprocidad sea un factor determinante de los términos en que ello ocurra. Este es el caso cuando la adquisición del derecho se condiciona al transcurso de un determinado plazo de residencia legal en España, distinto en función de la nacionalidad de procedencia del extranjero. Así, los extranjeros que procedieran de países en los que el mismo derecho es otorgado a nuestros nacionales verían su derecho reconocido en un plazo de tiempo inferior al exigido en el resto de los casos.

La interpretación de una norma constitucional no puede quedar anclada en el tiempo. La voluntad que tuviera constituyente al redactarla, siendo un criterio digno de atención, no debe erigirse en obstáculo definitivo a otras soluciones, especialmente en aquellos casos en los que, como aquí ocurre, el tenor literal del precepto permite nuevas interpretaciones más adaptadas a una realidad social completamente mudada, como consecuencia de un cambio que permite cuestionar con claridad el sentido que originariamente se quiso dar al precepto por sus redactores ${ }^{43}$.

La lectura que proponemos de la cláusula de reciprocidad abre nuevas posibilidades a la regulación de la materia a través de la ley, norma hasta ahora postergada en este ámbito a favor del tratado internacional bilateral. A este asunto dedicaremos el epígrafe siguiente.

\section{EL PROBLEMA DE LA FUENTE}

\subsection{La superación del tratado internacional como norma de atribución del derecho}

Como es sabido, el artículo 13.2 CE permite que el reconocimiento del derecho al sufragio de los extranjeros en las elecciones municipales pueda ser realizado por ley o por tratado internacional. Nuestro legislador, sin embargo, no ha hecho uso de la habilitación de la Constitución. En este sentido, el artículo 176.1 LOREG dispone que «(s)in perjuicio de lo regulado en el Título I, Capítulo I, de esta Ley, gozan del derecho de sufragio activo en las elecciones municipales los residentes extranjeros en España cuyos respectivos países permitan el voto a los españoles en dichas elecciones, en los términos de un Tratado».

43 Sobre cómo el cambio en las corrientes migratorias hace que pierda sentido la exigencia de reciprocidad, SANTOLAya Machetti, El derecho de sufragio..., cit., p. 513. 
Ciertamente su tenor literal resulta un tanto ambiguo, en la medida en que parece atribuir inmediatamente el derecho a los extranjeros («gozan») y remitir a los tratados únicamente los términos en que este se ejercería. Sin embargo, lo cierto es que el espíritu de la norma apunta a una remisión de la cuestión de la titularidad del derecho a los tratados internacionales y así ha sido entendido de manera unánime.

Esta remisión a los tratados contenida en el precepto legal ha suscitado algunas dudas en parte de la doctrina acerca de la constitucionalidad del precepto en este punto ${ }^{44}$. Sin embargo, el artículo 13.2 CE sitúa en el mismo plano a la ley y al tratado de cara al reconocimiento del derecho. Por ello, una ley que se limita a dejar en manos de los tratados la solución normativa se encuentra dentro del marco constitucional y no vulnera ninguna reserva normativa. La actual redacción del artículo 176 LOREG no cierra, ni puede cerrar, no obstante, la posibilidad de una futura reforma legislativa que atribuya directamente el derecho a los extranjeros.

Por su parte, el artículo 6 de la Ley orgánica 4/2000, de 11 de enero, sobre Derechos y Libertades de los Extranjeros en España y su Integración Social, modificado por la Ley Orgánica 2/2009, de 11 de diciembre, dispone que «(l)os extranjeros residentes en España podrán ser titulares del derecho de sufragio, en las elecciones municipales, en los términos establecidos en la Constitución, en los tratados internacionales, en su caso, y en la Ley». La cuestión de la titularidad del derecho queda así abierta al futuro ( «podrán ser titulares», pero no lo son) y nada se establece acerca de los términos en que esta posibilidad se pueda concretar, que son remitidos a la Constitución, los tratados y la ley.

Esta inactividad legislativa es tan solo un reflejo de la decisión política adoptada de utilizar el tratado como norma de atribución del derecho al voto a los extranjeros ${ }^{45}$. Este tratado debe ser tramitado de conformidad con el artículo 94.1 CE, toda vez que afecta a un derecho fundamental del Título I, como es el contenido en el artículo 23 CE. La prestación del consentimiento requiere, por tanto, la previa autorización de las Cortes Generales ${ }^{46}$.

${ }^{44}$ Con matices, Pérez Alberdi, op. cit., p. 99. A favor de la constitucionalidad de la norma examinada, Santolaya, Nacionalidad..., cit., p. 44.

45 Considera la vía de los tratados internacionales bilaterales la «más complicada y menos efectiva», IBÁÑEZ MAcías, El derecho de sufragio..., cit., p. 90. Contra la técnica del tratado bilateral, también AJA-Moya, op. cit., p. 22. Se muestran partidarios, por el contrario, del uso de los tratados, entre otros, Santolaya, Nacionalidad..., cit., p. 44; SAgarra Trías, La legislación..., cit., p. 110.

46 Sobre la exigencia de autorización de las Cortes Generales, entre otros, LozANo García, op. cit., p. 102; AJA-MoYA, op. cit., p. 20; IBÁÑEZ MACÍAs, El derecho de sufragio..., cit., p. 58. Se 
La opción por el tratado ha venido propiciada en buena medida por la comprensión que se ha realizado de la cláusula de reciprocidad ${ }^{47}$, al permitir su uso una clara definición de los Estados que satisfacen el citado requisito. Al mismo tiempo, su empleo deja al Gobierno un control evidente sobre las nacionalidades a las que se va a reconocer el derecho al sufragio en nuestras elecciones municipales.

El requisito de reciprocidad ha sido también la causa de que España no haya ratificado hasta al momento el Convenio Europeo sobre la Participación de los Extranjeros en la Vida Pública a Nivel Local, hecho en Estrasburgo el 5 de febrero de 1992 (en adelante, el Convenio Europeo) ${ }^{48}$. Este criterio carece de reflejo alguno en el texto del Convenio, que extiende el derecho a todos los extranjeros con independencia de cuál sea su Estado de procedencia, una vez cumplido un período máximo de cinco años de residencia en el Estado parte ${ }^{49}$.

Así, dejando a un lado lo relativo al reconocimiento del derecho en el ámbito de la Unión Europea, España ha ratificado hasta el momento doce tratados internacionales con este contenido: Noruega (BOE de 27 de junio de 1991), República de Ecuador (BOE de 5 de enero de 2010), Nueva Zelanda (BOE de 6 de enero de 2010), República de Colombia (BOE 21 de enero de 2010), República de Chile (BOE de 9 de febrero de 2010), República del Perú (BOE de 19 de mayo del 2010), República del Paraguay (BOE de 21 de junio de 2010), República de Islandia (BOE de 16 de diciembre de 2010), Estado Plurinacional de Bolivia (BOE de 17 de diciembre de 2010), República de Cabo Verde (BOE de 13 de enero de 2011), República de Corea (BOE de 6 de julio de 2011) y

muestra crítico con el recurso al instrumento del canje de notas, sin autorización de las Cortes, en el caso del acuerdo con Noruega, SAntolaya, Nacionalidad..., cit., p. 54.

47 Justifican su preferencia por los tratados en la garantía del cumplimiento de la exigencia de reciprocidad, Ferrer PeÑa, op. cit., p. 79 y MartíneZ-Pujalte, op. cit., p. 125.

48 Algún autor ha apuntado a la posibilidad de introducción de una reserva que supeditara el reconocimiento del derecho al cumplimiento del criterio de reciprocidad [SAGARRA TrIAS, E. (2008). «Los derechos políticos de los extranjeros en España: derecho de sufragio activo y pasivo en las elecciones municipales», en Balado Ruiz-Gallegos, M. (coord.), Inmigración, Estado y Derecho. Perspectivas desde el siglo XXI, Barcelona, Bosch, p. 331].

49 En contra, SANTOLAYA, para quien nada impediría a España aplicar el Convenio de forma coherente con el criterio de reciprocidad. El autor atribuye al Convenio el valor de un mero compromiso político, y no jurídico (Nacionalidad..., cit., P. 78). El ejemplo de Italia no puede ser, sin embargo, utilizado como argumento a favor de esta posición. Si bien es cierto que el tratado ha sido ratificado por Italia, cuyo texto constitucional reserva el derecho al voto a los nacionales, este país incorporó una Declaración por la que limitaba su aplicación a los capítulos A y B, con exclusión por tanto del C, donde se encuentra recogido el derecho al sufragio. Véase el texto de la Declaración en http://www.coe.int/en/web/conventions/full-list/-/conventions/treaty/144/ declarations?p_auth=haD864wC (última visita, 12/06/2017). 
República de Trinidad y Tobago (BOE de 2 de diciembre de 2011). El instrumento elegido en todos los supuestos ha sido el canje de notas.

Esta inclinación por el tratado bilateral como norma de referencia no deja de presentar, sin embargo, importantes desventajas. Por una parte, se hace depender nuestra decisión de reconocer un derecho fundamental a los extranjeros de la voluntad de negociar un tratado internacional, ya sea del país extranjero que cumple el requisito de reciprocidad, ya sea incluso de nuestro propio Gobierno ${ }^{50}$. Además, la técnica del tratado internacional no permite garantizar la existencia de una solución jurídica común para todos los $\operatorname{casos}^{51}$. De este modo, puede ocurrir que la situación en nuestro país de dos extranjeros, nacionales ambos incluso de Estados donde los españoles tengan reconocido el derecho al voto en sus elecciones municipales, sea distinta porque solo en uno de los casos se haya concluido un tratado internacional ${ }^{52}$. Por otro lado, la opción por el tratado impide la rápida adaptación del listado de nacionalidades beneficiarias de la medida a una realidad jurídica eventualmente cambiante. En definitiva, el uso del tratado internacional como norma de reconocimiento del derecho fundamental a los extranjeros se muestra incapaz de garantizar la máxima expansión del derecho entre todos sus destinatarios potenciales, con lo que ello supone de merma para el principio democrático.

Ante esta situación, parte de la doctrina ha optado por la propuesta de un modelo de articulación de ambas fuentes. De este modo, correspondería a la ley una labor inicial de definición de los criterios necesarios para poder verificar la presencia de reciprocidad, mientras que la ratificación del tratado supondría implícitamente el reconocimiento de la satisfacción de los requisitos legales ${ }^{53}$. A nuestro juicio, sin embargo, este modelo no mejoraría en nada la situación

$50 \mathrm{Al}$ respecto, MoyA, quien apunta además otros riesgos de la técnica convencional (op. cit., pp. 471-472).

51 Ibidem, p. 470.

52 García Mahamut entiende que, dándose los requisitos constitucionales establecidos en el artículo 13.2 CE, la ratificación de tratados solo con algunos países, y no con otros, «no solo podría vulnerar el principio democrático en el que se basan las elecciones sino que puede producir una quiebra del principio de igualdad al introducir un trato discriminatorio entre ciudadanos extranjeros» [GARCía MAHAMUT , R. (2011). «El derecho de sufragio de los extranjeros en España», en Álvarez CONDE, E. y otros (coords.), Estudios sobre la reforma de la Ley Orgánica del Régimen Electoral General. La reforma continua y discontinua, Madrid, Instituto de Derecho Público. Universidad Rey Juan Carlos, pp. 194-195].

53 Se muestran partidarios de esta intervención secuencial de ley y tratado, con matices entre ellos, IbáÑez Macías, El derecho de sufragio..., cit., p. 68; García MaHamut, op. cit., p. 194; Santolaya y Díaz Crego, op. cit., p. 121; Aja-Moya, op. cit., pp. 19-20; Moya, op. cit., pp. 469470; Santolaya, Nacionalidad..., cit., pp. 75-76. 
actual, en la que la ratificación de los tratados ya parte de una concepción laxa del criterio de reciprocidad. A la vista de la práctica política desarrollada hasta el momento, la intervención de la ley en el sentido propuesto no pasaría de ser un mero formalismo carente de consecuencias reales o, peor aún, podría tener como objetivo elevar un obstáculo más a la expansión del derecho, en el marco de un panorama ya de por sí deficiente.

Lo que aquí se sostiene es que se debe apostar por fin por la ley como único instrumento regulador en la materia, con abandono, por tanto, de la vía convencional seguida ${ }^{54}$. En el actual marco constitucional, y al amparo de la interpretación aquí propuesta de la cláusula de reciprocidad, la ley atribuiría con carácter general el derecho al sufragio, activo y/o pasivo, en las elecciones municipales a todos los extranjeros, en condiciones de igualdad ${ }^{55}$, salvo en lo relativo al plazo de residencia legal exigible, que sería variable en función de la existencia o no de un trato recíproco. A estos efectos, la norma legal podría remitir al Gobierno la tarea de especificar, antes de la celebración de cada proceso electoral, las nacionalidades respecto de las que constara el cumplimiento del requisito de reciprocidad. La alternativa consistente en hacer residir sobre cada extranjero la carga de la prueba ante la Administración electoral resultaría a todas luces disfuncional.

La sede apropiada para esta reforma legal sería la LOREG $^{56}$, concretamente su actual artículo 176, no así la Ley sobre derechos y libertades de los extranjeros en España, toda vez que, de acuerdo con la doctrina de la STC 38/1983 (F.J. 2), las elecciones municipales forman parte del régimen electoral general que constituye su objeto.

Esta apuesta por la ley como fuente de atribución a los extranjeros del derecho al voto en las elecciones municipales obliga a estudiar la constitucionalidad de la posible presencia en ella de cláusulas restrictivas. En efecto, abandonada la vía de los tratados bilaterales, y dada la generalidad de los términos que, en principio, caracterizan a la ley, el legislador podría plantearse la necesidad o conveniencia de limitar su alcance de acuerdo con distintos objetivos: excluir de la titularidad del derecho a los nacionales de determinados países, reducir la aplicabilidad de la norma bajo concretas circunstancias demográficas o, en el caso de Ceuta y Melilla, excluir los procesos electorales a sus respectivas Asambleas

54 Aunque desde una premisa distinta, partidarios del uso de la ley, LASAGABASTER HerrarTE, op. cit., pp. 76-77; OrTega Giménez-López Álvarez-Cano Esquibel, op. cit., p. 5.

55 Señala la ausencia de desigualdades entre inmigrantes procedentes de distintas nacionalidades como una de las ventajas de la vía legal, IBÁÑEz Macías, El derecho al sufragio..., cit., p. 68.

56 En este sentido, Santolaya Machetti, El derecho..., cit., p. 519. 
de la condición de elecciones municipales. A cada uno de estos asuntos dedicaremos los siguientes apartados.

\subsection{Sobre la posibilidad de limitar el alcance del reconocimiento legal del derecho}

\subsubsection{Exclusiones por razón de nacionalidad}

Hemos sostenido hasta el momento que la cláusula de reciprocidad prevista en el artículo 13.2 CE no impide la atribución por ley a todos los extranjeros del derecho al voto en las elecciones municipales, siempre que la existencia o no de reciprocidad sea tenida en cuenta a la hora de definir los plazos de residencia exigibles en cada caso. Lo que en este apartado nos planteamos es si, aun bajo la anterior premisa, podría procederse a la exclusión de determinadas nacionalidades de dicho reconocimiento o, a la inversa, si la propia ley podría disponer un catálogo cerrado y tasado de Estados de los que el extranjero ha de proceder para poder ser titular del derecho.

Ciertamente, los efectos excluyentes de esta ley no serían muy distintos de los que actualmente se derivan del uso de los tratados internacionales bilaterales como norma de atribución. Sin embargo, cuando el mecanismo utilizado para ello es la ley, la solución arroja importantes dudas sobre su constitucionalidad. La ausencia de precedente alguno en este sentido en el tratamiento legal de la titularidad por extranjeros de derechos fundamentales apoya la existencia de estas dudas.

El artículo 13.2 CE no parece ser suficiente argumento para autorizar una regulación de la materia en estos términos. Este precepto no otorga a la ley un poder ilimitado para decidir a quiénes reconocer el derecho. Más bien, establece una condición a su reconocimiento — la atención a criterios de reciprocidad- y una reserva de la función a dos instrumentos normativos: la ley o los tratados. De este modo, cada uno de estos tipos normativos queda sujeto a los condicionantes que les son propios. En el caso de los tratados internacionales, nada puede obligar al Gobierno a iniciar el procedimiento que puede concluir en la ratificación de uno de ellos. Solo a él corresponde esta decisión, en virtud del artículo 97 CE. La regulación de una materia sobre la base de tratados internacionales bilaterales implica, por tanto, necesariamente un componente de desigualdad en el régimen jurídico de los derechos de los extranjeros en función de su nacionalidad. La cuestión es si se puede pretender lograr este mismo efecto diferenciador por medio del uso de la ley.

El artículo 13.2 CE no exige un desarrollo por ley de esta materia, pero si tal norma fuera finalmente aprobada, su contenido habría de quedar inevitablemen- 
te sometido a las exigencias que derivan del derecho a no ser discriminado, previsto en el artículo 14 CE. Dada su vinculación con la garantía de la dignidad humana, su titularidad ha sido reconocida también a los extranjeros por el TC, por lo que estos no pueden ser discriminados por razón de su nacionalidad ${ }^{57}$. Este derecho, como es sabido, no veda todo trato diferenciado, sino únicamente aquel que carece de una justificación objetiva y razonable ${ }^{58}$. Resulta difícil, en principio, encontrar una razón capaz de justificar válidamente la exclusión de la titularidad del derecho al voto de los extranjeros de una determinada nacionalidad, ya sea con carácter general o específicamente para algunos municipios. A falta de tal motivación esta opción debería considerarse, por tanto, vedada.

\subsubsection{El criterio basado en el porcentaje de población extranjera residente}

La cuestión relativa a una eventual limitación del alcance de la ley que reconociera con carácter general el derecho al voto de los extranjeros en las elecciones municipales admite aún otra aproximación. Se trata ahora de analizar la constitucionalidad de la inclusión de medidas que redujeran el ámbito de aplicación del derecho de sufragio activo de los extranjeros no comunitarios en aquellos municipios en los que el porcentaje de extranjeros residentes superara un determinado nivel.

Tomemos como referencia para nuestro análisis una medida similar: la contenida en el artículo 12.1.a) de la Directiva 94/80/CE del Consejo, de 19 de diciembre de 1994, por la que se fijan las modalidades de ejercicio del derecho de sufragio activo y pasivo en las elecciones municipales por parte de los ciudadanos de la Unión residentes en un Estado miembro del que no sean nacionales. Este precepto permite, en los casos en los que la proporción de ciudadanos de la Unión en edad de votar residentes en un Estado miembro sin ostentar la nacionalidad del mismo fuese superior al $20 \%$ del conjunto de ciudadanos de la Unión en edad de votar y residentes en él, reservar el derecho de sufragio activo de los ciudadanos de la Unión Europea no nacionales a quienes lleven residiendo en dicho Estado miembro un período mínimo, que no puede ser superior a la duración de un mandato del órgano representativo municipal. El apartado 2 del citado precepto recoge incluso la posibilidad, para Bélgica, de aplicar esta medida en determinados municipios. En sus considerandos, la Directiva justifica la medida por problemas específicos que pudieran surgir en estos casos, sin dar mayores especificaciones sobre cuáles pueden ser estos.

57 Así, STC 137/2000, F.J. 1. Véase también al respecto la STC 236/2007, F.J. 3.

58 Por todas, STC 22/1981, F.J. 3. 
En nuestro supuesto, teniendo en cuenta que la norma ya podría contemplar la exigencia de un período de residencia, cabría la posibilidad de plantear un aumento del mismo en aquellos municipios en los que el porcentaje de extranjeros con derecho al voto superara el 20 por ciento del total del censo electoral. Una norma general con este contenido se enfrenta, sin embargo, a un importante obstáculo, que no es otro que determinar el fin que persigue. En el marco convencional actualmente vigente, los extranjeros no comunitarios solo pueden ejercer el derecho de voto en las elecciones municipales españolas si han residido en España de manera legal e ininterrumpida durante más de cinco años (tres años en el caso de Noruega). Este período de residencia debería ya garantizar, en sí mismo, si seguimos el propio punto de vista del estándar comunitario, la suficiente integración del extranjero en la vida social y política española, por lo que no tendría sentido aumentar el plazo de residencia requerido. Así pues, una medida de estas características solo podría contemplarse en el caso de que la nueva ley disminuyera el período de residencia requerido para el reconocimiento del derecho.

A dificultades aún mayores se enfrentaría la simple exclusión por la norma del derecho al voto de los extranjeros en tales casos. Desde la perspectiva del principio democrático, que sirve de base al reconocimiento del derecho al voto del extranjero en las elecciones municipales, la medida sería difícilmente explicable. Más aún, la elevada proporción de extranjeros en un municipio tan solo ahondaría en la necesidad de reconocer este derecho, so pena de excluir de la vida política del municipio a buena parte de las personas que van a quedar sujetas después a las normas aprobadas por sus órganos de gobierno. Ciertamente, como en el caso de cualquier otro gran colectivo, su influencia en el resultado electoral puede ser importante, e incluso decisiva. Aun así, ello no justificaría su exclusión. Distinta podría ser la conclusión si estuviéramos hablando del derecho al sufragio pasivo. Tal y como se afirma en los considerandos de la Directiva anteriormente citada, en tales casos podría ser un objetivo atendible el de evitar la polarización del electorado entre listas de candidatos nacionales y no nacionales. Una tal polarización va directamente en contra del objetivo de integración que persigue el reconocimiento del derecho. Este riesgo, sin embargo, no es trasladable al caso del derecho de sufragio activo, que constituye el objeto de este trabajo, por lo que habría que concluir la no viabilidad de la opción analizada.

\subsubsection{Los casos particulares de Ceuta y Melilla}

Hasta el momento, los procesos electorales celebrados a las Asambleas de Ceuta y Melilla han sido considerados elecciones municipales, también a los 
efectos del voto de los extranjeros. Sin duda, esta es la solución que favorece la mayor eficacia del derecho. No resulta descabellado, sin embargo, pensar que las peculiaridades que caracterizan la posición geopolítica de Ceuta y Melilla pudieran llevar en algún momento a una mayoría parlamentaria a plantearse el uso de fórmulas dirigidas a excluir a los extranjeros de la titularidad del derecho de sufragio en las elecciones a sus asambleas ${ }^{59}$. De hecho, la importancia de este asunto ha sido ya puesta de manifiesto por la doctrina, que en su momento llegó a señalar a la cuestión de Ceuta y Melilla en relación con Marruecos como la responsable de una cierta parálisis en la ratificación de este tipo de convenios ${ }^{60}$.

En la actualidad, la fórmula empleada en el texto de todos los tratados concluidos, excepción hecha del de Noruega, parece, de algún modo, otorgar cobertura a la posibilidad barajada, al tiempo que sugerir la vía a utilizar: la no catalogación de las elecciones a las Asambleas de Ceuta y Melilla como elecciones locales. Esto es así porque en uno de sus considerandos, el dedicado a describir los tres tipos de elecciones existentes en España, los acuerdos hacen referencia a las generales, para las instituciones centrales, las municipales y, en la formulación más común, "para los Entes territoriales dotados de Estatuto de Autonomía, elecciones a sus Asambleas». No se hace, pues, referencia expresa a las Comunidades Autónomas, sino que se utiliza un giro que sirve perfectamente para abarcar a Ceuta y Melilla, con lo que su exclusión no tendría que plantear ningún problema desde un punto de vista convencional ${ }^{61}$.

Sería, sin embargo, necesario dilucidar si existe algún argumento basado en la Constitución por el que las elecciones a las asambleas de Ceuta y Melilla tengan que regirse necesariamente por las normas que regulan las elecciones municipales. En este sentido, a favor de la existencia de dicho vínculo podría traerse a colación la jurisprudencia sentada en la STC 240/2006, donde el alto Tribunal, recordando una doctrina propia anterior donde se negaba la condición de Ceuta y Melilla como Comunidades Autónomas ${ }^{62}$, fundamenta la definición de ambas como entes municipales en diversos preceptos de sus respectivos Estatutos de Autonomía (F.J. 4).

59 Sobre la titularidad por los extranjeros del derecho al voto en las elecciones a las Asambleas de Ceuta y Melilla, García Mahamut, op. cit., pp. 189 y ss. Martínez-Pujalte se hace eco de que la admisión de la exclusión impuesta por Perú del derecho al voto de los españoles en el ámbito de los municipios fronterizos se justificó en el Congreso por razones de seguridad nacional. Considera probable este autor «que esta limitación se haya admitido para abrir la puerta a una futura excepción similar por parte de España para los casos de Ceuta y Melilla», considerando «plausible» este deseo (op. cit., pp. 126-127).

60 Santolaya, Nacionalidad..., cit., pp. 25-26.

61 Como afirma García MaHAmut, «(l)a cuestión, en todo caso, se encuentra en la naturaleza de la elección» (op. cit., p. 192).

62 AATC 201/2000 y 202/2000. 
De este modo — podría sostenerse- - si se considera a Ceuta y Melilla como entes municipales, el régimen jurídico por el que se debe regular las elecciones a sus respectivas asambleas tiene que ser el propio de dichos entes.

Sin embargo, un análisis más detenido de la resolución citada nos muestra que su objetivo no era poner punto y final al debate doctrinal sobre la naturaleza jurídica de Ceuta y Melilla, sino más bien tomar una decisión acerca de cuál habría de ser la vía por la que ambas ciudades podrían acceder al Tribunal Constitucional. Cerrada para ellas en un primer momento la posibilidad de utilizar el recurso de inconstitucionalidad con el argumento de que no son propiamente Comunidades Autónomas, y una vez creado por el legislador el conflicto en defensa de la autonomía local, el Tribunal se ve obligado a reconocer su legitimidad activa en dicho proceso para no situarlas en peor situación ante él que los propios entes municipales. Así se deduce claramente del siguiente inciso:

«Excluida la posibilidad de que las ciudades de Ceuta y Melilla constituyan sendas Comunidades Autónomas, y como quiera que tampoco se integran en la organización provincial del Estado, no cabe negarles, al menos a los efectos de poder acceder ante el Tribunal Constitucional en defensa de su autonomía, su condición de entes municipales» (la cursiva es nuestra).

Sin ánimo de entrar ahora en la polémica doctrinal acerca de la naturaleza jurídica de Ceuta y Melilla, parece evidente que es, precisamente, el reconocimiento de su peculiaridad como entes territoriales lo que está a la base de su tratamiento constitucional. Así, como es sabido, la Disposición Transitoria 5. CE llega a permitirles incluso su constitución en Comunidades Autónomas, aunque finalmente la aprobación de sus respectivos Estatutos de Autonomía llegara por la vía del artículo 144.b) CE en tanto que entes no integrados en la organización provincial. Esto último ya es, en sí mismo, un rasgo distintivo fundamental de Ceuta y Melilla respecto del resto de municipios españoles: son los únicos entes municipales no integrados en la organización provincial ni, por tanto, en una Comunidad Autónoma en sentido estricto.

Esta peculiaridad es capaz, sin duda, de justificar la presencia de rasgos distintivos en su régimen jurídico. Como señala el TC en la sentencia citada:

«Ceuta y Melilla son entes municipales dotados de un régimen de autonomía local singular, reforzado respecto del régimen general de los demás municipios, que viene regulado por las previsiones específicas contempladas para ambas ciudades en sus respectivos estatutos de autonomía en cuanto a su estructura organizativa, sistema de competencias, régimen jurídico, mecanismos de cooperación con la Administración del Estado y régimen económico y financiero, especialmente» (la cursiva es nuestra). 
Por otra parte, la extensión del derecho al voto de los extranjeros aparece en nuestra Constitución como una excepción reducida a las elecciones municipales. Este carácter excepcional justificaría una interpretación restrictiva por parte del legislador de lo que deba considerarse municipio a estos efectos, y, con ello, la exclusión del régimen jurídico de las elecciones municipales, al menos en el aspecto que aquí interesa.

Tampoco se puede olvidar en este sentido que el régimen jurídico de las elecciones a las Asambleas de Ceuta y Melilla actualmente vigente ya contempla una importante excepción respecto del propio de las elecciones municipales, y precisamente en un punto estrechamente conectado con el que aquí nos ocupa: nos referimos al voto de los residentes ausentes ${ }^{63}$. En efecto, la LO 2/2011, de 28 de enero, por la que se modifica la Ley Orgánica 5/1985, de 19 de junio, del Régimen Electoral General, excluye a estas personas del derecho al voto en las elecciones municipales con la intención, recogida en su Preámbulo, de seguir la recomendación del Consejo de Estado de unir, en línea con lo dispuesto en el artículo $140 \mathrm{CE}$, el ejercicio del derecho de sufragio en elecciones municipales a la condición de vecino de un municipio. A pesar de ello, la LOREG equipara, en su artículo 75, a estos efectos, las elecciones a miembros de las Asambleas de Ceuta y Melilla a las elecciones a Diputados, Senadores, miembros de las Asambleas Legislativas de las Comunidades Autónomas o Diputados al Parlamento Europeo. En definitiva, el régimen jurídico de las elecciones a las asambleas de Ceuta y Melilla es el propio de las elecciones municipales, por lo que respecta al derecho de sufragio activo de los extranjeros, mientras que es el de las elecciones generales o autonómicas en lo que concierne al voto de los residentes ausentes ${ }^{64}$.

Sin embargo, aunque la norma constitucional no parece plantear problema alguno a la posibilidad de exceptuar a Ceuta y Melilla de la posible atribución por ley a los extranjeros del derecho al voto en las elecciones municipales, algo distinto podría ocurrir en el plano estatutario ${ }^{65}$. En este sentido, la Junta Elec-

63 Apunta a este elemento, García Mahamut, op. cit., p. 191.

${ }^{64}$ Un análisis crítico de esta medida en Balaguer Callejón, M. L. (2016). «Las garantías en el Derecho electoral y la regulación de la participación política de los españoles residentes en el extranjero», Revista Europea de Derechos Fundamentales, núm. 27, p. 124.

65 De hecho, es en los propios estatutos de autonomía de ambas Ciudades Autónomas donde podría encontrarse también la justificación de la excepción hecha con ambas por el legislador orgánico en lo relativo al voto de los residentes ausentes, que antes se ha mencionado, en la medida en que ambos reconocen dicho derecho en las elecciones a sus asambleas. En este sentido, el artículo 4.2 de sus respectivos Estatutos de Autonomía dispone que: «(g)ozan también como ceutíes (melillenses) de los derechos políticos reconocidos en el presente Estatuto los ciudadanos españoles residentes en el extranjero que hayan tenido su última vecindad administrativa en el Municipio de Ceuta (Melilla) y acrediten esta circunstancia en el correspondiente Consulado de 
toral Central (en adelante, JEC) afirmó en un Acuerdo de 27 de abril de 1999 que

«(d)ado que el artículo 8 del Estatuto de Ceuta y el del mismo número del de Melilla atribuyen la condición de elector y elegible a los ciudadanos mayores de edad y que estén en pleno uso de sus derechos políticos y cumplan con los requisitos establecidos en la legislación estatal regladora del régimen electoral general para la celebración de "elecciones locales" ${ }^{66}$, el derecho de sufragio en las elecciones de Ceuta y Melilla se ostenta, aparte de por los ciudadanos españoles, por: 1. ${ }^{\circ}$ Los ciudadanos de países de la Unión Europea residentes en Ceuta y Melilla, los cuales tienen derecho de sufragio activo y pasivo en las elecciones a las Asambleas de dichas ciudades Autónomas. 2. ${ }^{\circ}$ Los ciudadanos noruegos residentes en Ceuta y Melilla tienen el derecho de sufragio activo, pero no el pasivo, en las elecciones de las Asambleas de dichas ciudades autónomas» ${ }^{67}$.

Posteriormente, la JEC ha entendido que este último criterio es aplicable a los Tratados de reciprocidad suscritos posteriormente por España ${ }^{68}$.

En definitiva, nuestra Constitución permitiría cambiar la actual consideración de las elecciones a las asambleas de Ceuta y Melilla como elecciones municipales, a los efectos de la atribución a extranjeros del derecho al sufragio en ellas, si bien cualquier modificación respecto de la solución vigente en estos momentos debería venir, si no adoptada, sí al menos precedida de una reforma del mencionado artículo 8.1 de las respectivas normas estatutarias, que ha servido de base hasta la fecha para la atribución del derecho a los nacionales de países con los que España tiene ya ratificado un tratado bilateral ${ }^{69}$.

España, así como los descendientes de éstos, inscritos como españoles, si así lo solicitasen, en la forma que determine la Ley del Estado».

66 Según el artículo 8.1 del Estatuto de Ceuta, «Serán electores y elegibles los ciudadanos mayores de edad que estén en pleno uso de sus derechos políticos y cumplan con los requisitos establecidos en la legislación estatal reguladora del régimen electoral general para la celebración de elecciones locales, si bien tanto en la documentación que se tramite como en las papeletas de voto constará expresamente la mención "Elecciones a la Asamblea de Ceuta"». Idéntico tenor literal tiene mutatis mutandi el artículo 8.1 del Estatuto de Melilla.

${ }^{67}$ El mismo argumento de la Junta Electoral Central fue con anterioridad usado por el Consejo de Estado para reconocer el derecho de sufragio de los extranjeros comunitarios en las elecciones a las asambleas de Ceuta y Melilla (dictamen de 22 de abril de 1999). Sobre el tema, véase Fraile OrTiz, M. (1999). «Alcance del derecho de sufragio activo y pasivo de los extranjeros residentes en las ciudades de Ceuta y Melilla», Cuadernos de Derecho Público, núm. 8, pp. 139 y ss.

${ }_{68}$ Por todos, Acuerdo de la JEC de 27 de enero de 2011, apartado 2. ${ }^{\circ}$, ratificado por Acuerdo de 9 de octubre de 2014.

${ }^{69}$ Aunque se escapa del objetivo de este trabajo el estudio en profundidad del alcance que debería tener esta reforma, en todo caso parece que sería necesario extenderla también a otros preceptos estatutarios que vinculan estos procesos electorales a las elecciones municipales, tales 


\section{LAS CONDICIONES DE EJERCICIO DEL DERECHO AL SUFRAGIO ACTIVO DE LOS EXTRANJEROS EN LAS ELECCIONES MUNICIPALES}

\subsection{Limites a la actuación legislativa}

Hasta ahora se ha sostenido en este trabajo que la cláusula constitucional de reciprocidad tan solo obliga a que la norma de atribución del derecho tenga en cuenta dicho criterio. Esta nueva concepción abre las puertas al reconocimiento general de los extranjeros como titulares del derecho al voto en las elecciones municipales, sujeto al cumplimiento de un período de residencia legal que deberá ser variable en función de la concurrencia o no, en cada caso, de reciprocidad. Este nuevo panorama, más conforme con el principio democrático, hace deseable la intervención de la ley como norma de atribución del derecho. En este epígrafe pretendemos analizar cuál es el margen del que dispone el legislador a la hora de establecer las condiciones de ejercicio del derecho, para lo que será necesario partir de la doctrina consolidada por el TC acerca de los derechos fundamentales de los extranjeros. Con ello, estaremos en condiciones de posicionarnos acerca del requisito, actualmente exigido a los extranjeros titulares del derecho, de inscripción a instancia de parte en el censo electoral.

Como es sabido, el TC ha consolidado una clasificación de los derechos fundamentales en cuatro tipos diferentes, en función de la posibilidad de ser reconocidos a los extranjeros. Así, el TC ha distinguido entre aquellos que no pueden ser extendidos por el legislador a los extranjeros por prohibirlo expresamente el artículo $13.2 \mathrm{CE}$; los que corresponden a los extranjeros por propio mandato constitucional, en virtud de su estrecha vinculación con la dignidad de la persona; aquellos otros que, identificados principalmente por la expresión utilizada por la norma constitucional para definir a sus titulares, la Constitución reconoce directamente a los extranjeros y, finalmente, un último grupo que la Constitución atribuye a los españoles, pero de los que serán titulares los extranjeros, en virtud de lo dispuesto en el artículo $13.1 \mathrm{CE}$, «en la medida y condiciones que se establezcan en los Tratados y las Leyes» (STC 236/2007, F.J. 4).

Por lo que respecta concretamente al derecho al sufragio activo en las elecciones municipales, nos encontramos ante un derecho que no es atribuido directamente por la Constitución a los extranjeros, si bien el legislador puede extenderlo a los no nacionales. Esto parece reconducir el derecho que nos ocupa a la última de las categorías mencionadas, lo que implicaría, según la citada cons-

como el 7.1, que hace idéntica remisión a lo dispuesto por la LOREG para las elecciones locales, esta vez con carácter general. 
trucción jurisprudencial, que su reconocimiento no tendría por qué ser, necesariamente, en los mismos términos que a los españoles (SSTC 94/1993, F.J. 3; 236/2007, F.J. 4). Si así fuera, le sería aplicable la consideración del TC por la que

«(a)l regular tales derechos la libertad del legislador es más amplia ya que puede modular las condiciones de ejercicio "en función de la nacionalidad de las personas, introduciendo tratamientos desiguales entre españoles y extranjeros" si bien aquella libertad «no es en modo alguno absoluta» (STC 94/1993, de 22 de marzo, F.J. 3)» (STC 236/2007, F.J. 4).

Sin embargo, lo que aquí vamos a sostener es que el estudio del tratamiento constitucional del derecho al sufragio activo de los extranjeros en las elecciones municipales no se puede abordar desde esta conocida distinción, en la que el derecho no llega a encajar en virtud de determinados elementos de su configuración. De hecho, este derecho es prácticamente ignorado por el TC en su construcción, cuyas sentencias se limitan a dedicarle, en el mejor de los casos, una ínfima referencia al hilo de la mención a la categoría de derechos cuya extensión a los extranjeros está prohibida por la Constitución, en tanto que excepción dentro de la misma.

El carácter sui generis del derecho encuentra su reflejo en el propio texto constitucional. En efecto, se trata del único derecho fundamental que, pudiendo ser ejercido por los extranjeros, merece un tratamiento diferente y separado del resto. Su ubicación en el artículo 13.2 CE no debe ser considerada, por tanto, irrelevante, sino más bien un reconocimiento de su peculiaridad dentro de la Norma Suprema. Por otra parte, el precepto mencionado aborda la cuestión únicamente desde la perspectiva de la titularidad del derecho, y no, como sucede en el artículo 13.1 CE, también desde su ejercicio ${ }^{70}$. La Constitución habilita a la ley o al tratado para reconocer o no la titularidad del derecho a los extranjeros, siempre de acuerdo con criterios de reciprocidad, pero calla sobre la posibilidad de prever para él un régimen jurídico distinto en función de que su titular sea o no español.

Esta especificidad de su tratamiento constitucional se encuentra en línea con la propia naturaleza del derecho al sufragio y su íntima vinculación con la condición de ciudadano. El artículo 13.1 CE proyecta la dicotomía «español-extranjero» sobre algunos de los derechos reconocidos en el título primero de la Cons-

70 En palabras del Consejo de Estado, en su Dictamen núm. 421/92, de 9 de abril de 1992, sobre el Expediente relativo al Tratado de la Unión Europea firmado en Maastricht el 7 de febrero de 1992, «(e)l artículo 13.2 no se refiere al contenido esencial de los derechos que reconoce el artículo 23 , sino al círculo de sujetos titulares de tales derechos». 
titución. El artículo 13.2 CE, sin embargo, supera el planteamiento del citado precepto y obliga a analizar la cuestión abordada desde otro prisma, esto es, desde un binomio diferente: el de «ciudadano-no ciudadano».

Como afirma el TC,

«nuestro ordenamiento no desconstitucionaliza el régimen jurídico de los extranjeros, el cual tiene su fuente primera en el conjunto del texto constitucional. En concreto, la titularidad y el ejercicio de los derechos fundamentales de los extranjeros en España deben deducirse de los preceptos que integran el título I, interpretados sistemáticamente. Para su determinación debe acudirse en primer lugar a cada uno de los preceptos reconocedores de derechos que se incluyen en dicho título, dado que el problema de su titularidad y ejercicio "depende del derecho afectado" (STC 107/1984, de 23 de noviembre, F.J. 4). Y en segundo lugar, a la regla contenida en el artículo 13 CE», en sus dos apartados (STC 236/2007, F.J. 3).

Por lo que respecta al derecho que nos ocupa, en la Declaración 1/1992 del TC se puede leer lo siguiente:

«no es el artículo 23 el precepto que en nuestra Constitución establece los límites subjetivos determinantes de la extensión de la titularidad de los derechos fundamentales a los no nacionales. En nuestra Constitución dicha norma, atinente a este requisito de la capacidad, no es el artículo 23, sino el artículo 13» [F.J. 3. B)].

La exclusión de los extranjeros de la titularidad del derecho de sufragio activo en las elecciones municipales «no deriva, por tanto, de las previsiones del artículo 23, que por sí mismo no prohíbe que los derechos así reconocidos puedan extenderse, por Ley o Tratado, a los ciudadanos de la Unión Europea», afirmación extensible a cualquier otro extranjero.

El artículo 23 CE otorga el derecho de participación en los asuntos públicos a «los ciudadanos», lo que ha venido siendo interpretado en el sentido de que su titularidad requiere tal condición, unida tradicionalmente a la nacionalidad. Sin embargo, el efecto principal del artículo 13.2 CE sobre el derecho del artículo 23.1 CE consiste precisamente en la habilitación al legislador para la ruptura de dicho vínculo, aun en el limitado ámbito de las elecciones municipales, con la correspondiente atribución allí mismo al extranjero del estatuto de ciudadano.

Esto no supone en modo alguno una quiebra en el uso que nuestra Norma Suprema realiza del término «ciudadano», que ya ha sido empleado en algunos contextos para referirse a todas las personas, con independencia de su nacionali- 
$\mathrm{dad}^{71}$. Por lo que respecta a su significado en el artículo 23.1 CE, es precisamente el propio artículo 13.2 CE el que permite, con su segundo inciso, fragmentar el concepto, admitiendo su extensión a extranjeros en el ámbito de las elecciones municipales y negándolo para los restantes niveles de representación ${ }^{72}$.

De algún modo esta posición ya aparece reflejada en la jurisprudencia constitucional $^{73}$. El propio TC ha apuntado a que el requisito de la nacionalidad para el ejercicio del derecho de sufragio (en el caso en cuestión era el sufragio pasivo, pero la consideración es extensible al activo) «admite la excepción que se establece en el artículo 13.2» de la Constitución (STC 86/2003, F.J. 4). Por otra parte, cuando el TC afirma que existen en el Título I derechos, los reconocidos en el artículo 23 , reservados en exclusiva a los españoles, cuya extensión a los extranjeros por el legislador viene vedada por el artículo 13.2 CE, añade: «con la salvedad que contiene» [SSTC 107/1984,

71 Cfr. Sagarra Trías, La legislación..., cit., pp. 61-62; Rodríguez Ruiz, B. (2016)., «Las dos caras de la ciudadanía moderna: entre la nacionalidad y el estatus participativo», Revista Europea de Derechos Fundamentales, núm. 27, p. 36. Sobre las distintas opciones interpretativas que admite el término «ciudadanos» en el artículo 23.1 CE, IBÁÑEz MACíAs, A. (2007). El derecho constitucional a participar y la participación ciudadana local, Madrid, Difusión Jurídica y Temas de Actualidad, 2007, pp. 133-134, 141-145; Vidal Fueyo, M. a del C. (2002). Constitución y extranjería. Los derechos fundamentales de los extranjeros en España, Madrid, Centro de Estudios Políticos y Constitucionales, p. 69, especialmente en la nota 63. Interpreta el término «ciudadanos» del artículo 23 CE como equivalente a «nacionales», SANTOlaya Machetti, Los Acuerdos..., cit., pp. 17-18. En contra de esta posición, VIDAL FuEYo, Constitución y extranjería..., cit., p. 69; ALÁEZ Corral, B. (2006). Nacionalidad, ciudadanía y democracia. ¿A quién pertenece la Constitución?, Madrid, Centro de Estudios Políticos y Constitucionales/Tribunal Constitucional, p. 231 o AgUDo Zamora, M. (2016). «Vías constitucionales para el reconocimiento del derecho de sufragio en las elecciones autonómicas españolas a los extranjeros residentes», Revista Europea de Derechos Fundamentales, núm. 27, p. 316. Sobre la disociación de los conceptos de nacionalidad y ciudadanía en el artículo 13.2 CE véanse el informe del Consejo de Estado, op. cit., p. 35, SANTOLAYA Y Díaz Crego, op. cit., p. 15; García Mahamut, op. cit., p. 178; Massó Garrote, op. cit., p. 128; Rodríguez-Drincourt Álvarez, op. cit., p. 334.

72 En este sentido, Revenga SÁnCHEZ, op. cit., p. 86. Esta posición encaja con las palabras de Aláez Corral, para quien «la existencia de diversos ámbitos materiales de integración social del individuo deja claro que la ciudadanía es una institución jurídica graduable que se corresponde con diversos círculos personales (ciudadanos españoles y ciudadanos extranjeros) o territoriales (ciudadanía nacional, autonómica o local)» (op. cit., p. 232). En relación con la participación de extranjeros residentes en las elecciones municipales, habla de «la existencia de nuevas esferas de ciudadanía» (ibídem, p. 244) o de un aumento en su grado de ciudadanía política (ibídem, p. 246). En contra de la propuesta de Aláez Corral, Santolaya Machetti, Los Acuerdos..., cit., p. 18.

73 Cfr. Rodríguez, A. (2016). «El voto de los ciudadanos de la Unión Europea en las elecciones autonómicas españolas: estado de la cuestión y propuestas de reforma», Revista Europea de Derechos Fundamentales, núm. 27, p. 218. 
F.J. 4; 236/2007, F.J. 3; 17/2013, F.J. 2; en términos similares, la Declaración $1 / 1992$, F.J. 3. B)].

Por otro lado, el requisito de residencia legal en España durante un lapso de tiempo determinado, previsto por los tratados, adquiere pleno sentido desde la lectura de la Constitución que aquí se propone. La ciudadanía, que implica la atribución de una serie de derechos de participación ${ }^{74}$, supone conceptualmente el necesario reconocimiento en la persona de un vínculo suficientemente relevante con el ordenamiento de referencia. En el caso de los españoles este nexo de unión viene determinado por la mera nacionalidad; en el de los extranjeros, sin embargo, ha de acudirse a otro expediente: la residencia ${ }^{75}$. Esto resulta plenamente conforme con el significado del principio democrático, pues solo cuando ella concurre durante un plazo suficiente se puede presumir el interés del extranjero en participar en la elección de unos representantes que van a quedar luego encargados de definir las políticas públicas de las que él mismo será eventualmente destinatario.

La satisfacción del requisito temporal se demanda de la residencia en el territorio nacional, no en el municipal. El extranjero debe haber residido durante un determinado plazo en España, no en el concreto municipio en el que puede finalmente ejercer su derecho al voto. Sin embargo, en la medida en que se trata de un proceso electoral de ámbito municipal, esto no es suficiente para ejercer el derecho al voto. Del artículo 140 CE resulta una ineludible vinculación entre el sufragio activo en las elecciones municipales y la condición de vecino, lo que explica la exigencia, por parte de los tratados, de empadronamiento en el municipio en el que se pretende votar, circunstancia que, como dispone el artículo 15

74 Para Aláez Corral, «se puede hablar de ciudadanía allí donde haya un poder jurídico que contemple a sus súbditos —nacionales o extranjeros, hombres o mujeres, residentes o ausentes, mayores o menores - como sujetos de derechos y no como meros objetos de la regulación jurídica, esto es, donde les confiera ciertas capacidades de participación en el proceso comunicativo, incluyéndoles dentro del mismo» (op. cit., p. 199).

75 En esta materia acuden a la residencia como criterio para determinar la ciudadanía, entre otros muchos, Chueca Sancho, A. G. y Aguelo Navarro, P. (2009). «El derecho de voto de los extranjeros en España en perspectiva europea», Documentos Cidob, Migraciones, 19, p. 20 (disponible en http://www.pensamientocritico.org/cheagu0909.pdf; última visita: 13/06/2017); Aláez Corral, op. cit., p. 291; Ortega Giménez, op. cit., p. 21; García Soriano, op. cit., p. 261; De Asís Roig, op. cit., p. 199 y 217; García VÁzQuez, op. cit., p. 226; Presno Linera, El voto de los extranjeros..., cit., pp. 193-195. El Consejo de Estado sostiene en su informe que la apertura a la residencia como criterio de ciudadanía «es reflejo del artículo 13.2 de nuestra Constitución» (op. cit., p. 35). 
de la Ley reguladora de las Bases del Régimen Local (en adelante, LBRL), implica la adquisición de la vecindad ${ }^{76}$.

También parece razonable entender que el ejercicio de un derecho al sufragio activo vinculado a la condición de ciudadano no es compatible con la situación de irregularidad en la que pudiera encontrarse el extranjero, lo que viene a apoyar la exigencia de los tratados de que la residencia sea legal ${ }^{77}$. Resulta aquí de aplicación la doctrina del TC por la que

«el legislador puede tomar en consideración el dato de su situación legal y administrativa en España, y exigir a los extranjeros la autorización de su estancia o residencia como presupuesto para el ejercicio de algunos derechos constitucionales que por su propia naturaleza hacen imprescindible el cumplimiento de los requisitos que la misma ley establece para entrar y permanecer en territorio español» (STC 236/2007, F.J. 4).

En cuanto al plazo de residencia exigible, cabría plantearse si sería conforme con la Constitución la existencia de un régimen diverso en función de la nacionalidad. Se trataría entonces de reconocer a los extranjeros por distintas razones (históricas, políticas, culturales, etc.) un diverso grado de vinculación con nuestro país en función de su lugar de procedencia. Este criterio no es ajeno en realidad al propio texto constitucional. Como es sabido, el artículo 11.3 CE permite concertar tratados de doble nacionalidad «con países iberoamericanos o con aquellos que hayan tenido o tengan una particular vinculación con España». Si la Constitución acude a este criterio en una materia como la nacionalidad, con el efecto que esta conlleva respecto de la adquisición de la plena titularidad de todos los derechos fundamentales, con mayor razón podría utilizarse en relación con un aspecto singular de uno de ellos: el sufragio activo en las elecciones municipales $^{78}$. No puede olvidarse además que el régimen jurídico actualmente

76 Sobre la influencia del artículo 140 CE en la materia, véase CARrasco Durán, op. cit., p. 152; IBÁÑEZ MaCíAs, El derecho de sufragio..., cit., op. cit., p. 63. Una crítica a la desvinculación legal entre la adquisición de la vecindad administrativa y la residencia estable en el municipio, en Aláez Corral, op. cit., pp. 292-293.

77 En este sentido, véase el informe del Consejo de Estado, p. 63. No aprecia discriminación en la distinción entre residentes legales e ilegales a la hora de reconocer los derechos de sufragio a los extranjeros, IBÁÑEZ Macías, El derecho de sufragio..., cit., pp. 61-62. Limita también la aplicación del criterio de residencia a los extranjeros legales, entre otros, OrTEGA GimÉnEz, op. cit., p. 21.

$78 \mathrm{Al}$ respecto, véanse el informe del Consejo de Estado, pp. 37, 61, 63 y 64 u OrTEGA Giménez, op. cit., p. 21. Considera «difícil de justificar» una diferencia de trato por razón de la nacionalidad en el caso de extranjeros extracomunitarios, respecto del período de residencia mínimo exigido IBÁÑEZ Macías, El derecho de sufragio..., cit., pp. 62-63. 
vigente sobre el tema ya contempla esta diferenciación, toda vez que la LOREG no impone un período concreto de residencia a los ciudadanos comunitarios para poder ejercer su derecho, mientras que el exigido por los tratados ratificados oscila entre los tres y los cinco años ${ }^{79}$. Así pues, queda en manos del legislador la apreciación del período de tiempo que es razonablemente exigible a los nacionales de los distintos países para poder presumir la creación de ese vínculo con nuestro ordenamiento determinante de la condición de ciudadano ${ }^{80}$.

En definitiva, por lo que respecta al derecho al sufragio activo en las elecciones municipales, una interpretación conjunta del artículo 23.1 en relación con el 13.2 CE obliga a entender superado el binomio «nacional-extranjero» en favor de la ciudadanía como categoría unitaria. Se hace necesario, de este modo, reelaborar el criterio por el que el TC ha venido clasificando los derechos fundamentales en función de que los extranjeros pudieran o no ser titulares de los mismos. Así, se podría pasar a distinguir entre derechos cuyo tratamiento jurídico depende (caso de los derechos de participación referidos en el primer inciso del artículo $13.2 \mathrm{CE}$ ) o puede depender de la nacionalidad, otros que son reconocidos a todas las personas, a la vista de su vinculación con la dignidad, y, finalmente, otro - el derecho de sufragio activo y pasivo en las elecciones municipalespara el que la variable de la nacionalidad se torna irrelevante y es sustituida por la de ciudadanía.

Este nuevo planteamiento no puede dejar de tener también repercusiones en lo que respecta al margen de libertad del legislador para configurar las condiciones de ejercicio del derecho. De acuerdo con la tradicional vinculación existente entre ciudadanía e igualdad ${ }^{81}$, una vez atribuida al extranjero la condición de

79 Este aspecto lo reconoce el Consejo de Estado en su informe (op. cit., p. 63).

80 Distintas posiciones sobre los plazos exigibles en el informe del Consejo de Estado (ibídem, p. 64); Aláez Corral, op. cit., pp. 293-294; Presno Linera, El voto de los extranjero..., cit., p. 204; IBÁÑEz Macías, El derecho de sufragio..., cit., p. 63. Para OrTEGA GimÉnEZ, «la propuesta de firmar acuerdos de reciprocidad servirá de muy poco si se exige para votar un período de residencia en España de entre tres y cinco años, pues en dicho período el extranjero, si lo desea, podría ya haber alcanzado la nacionalidad española» (op. cit., p. 38). En el mismo sentido, OrTEga Giménez-López Álvarez-Cano Esquibel, op. cit., p. 14.

81 Así, Santolaya, Nacionalidad..., cit., p. 31. Esta exigencia de igualdad ha sido vista con claridad en el ámbito de la Unión Europea. Así, en los siguientes considerados de la Directiva 94/80/CE del Consejo, de 19 de diciembre de 1994, por la que se fijan las modalidades de ejercicio del derecho de sufragio activo y pasivo en las elecciones municipales por parte de los ciudadanos de la Unión residentes en un Estado miembro del que no sean nacionales, modificada por la Directiva 96/30/CE, de 13 de mayo de 1996, se puede leer: «(c)onsiderando que el derecho de sufragio activo y pasivo en las elecciones municipales en el Estado miembro de residencia, contemplado en el apartado 1 del artículo 8 B del Tratado constitutivo de la Comunidad Europea, supone una aplicación del principio de igualdad y de no discriminación entre ciudadanos nacio- 
ciudadano, la nacionalidad del titular del derecho no debería ser un factor a tener en cuenta para la construcción de tratamientos jurídicos diferenciados, salvo que existiera una específica justificación objetiva y razonable para ello. La ciudadanía nivela así el estatus de todas las personas que la integran, por lo que cualquier diferencia en el trato por ellas recibido del ordenamiento debe poder superar el test de discriminación.

Esta conclusión encuentra su reflejo incluso en la propia jurisprudencia constitucional relativa a la materia. Cuando el TC habla de los derechos «que corresponden a los extranjeros por propio mandato constitucional, y no resulta posible un tratamiento desigual respeto de los españoles» (STC 107/1984, F.J. 3; 236/2007, F.J. 3), justifica su posición en el hecho de que estos derechos «pertenecen a la persona en cuanto tal y no como ciudadanos, o dicho de otro modo, se trata de derechos que son imprescindibles para la garantía de la dignidad humana que conforme al artículo 10.1 de nuestra Constitución es el fundamento del orden político español» (STC 236/2007, F.J. 3, con cita de abundante jurisprudencia). El TC emplea aquí el término «ciudadanos» en su acepción restringida, que lo hace equivaler a «nacionales». De este modo, cuando, como sucede en el caso del derecho al sufragio activo de los extranjeros en las elecciones municipales, el reconocimiento del derecho se hace girar en torno a una misma condición de la persona como ciudadana, esta vez desvinculada de la nacionalidad, se impone idéntica conclusión: la imposibilidad de un tratamiento desigual entre españoles y extranjeros.

En todo caso, y por lo que es de utilidad para los fines que aquí perseguimos, la necesidad de sujetar a límites la actividad legislativa sobre el derecho se deriva, incluso, de la mencionada clasificación del TC. Así, la STC 236/2007 sostiene que al establecer restricciones y limitaciones a los derechos de la categoría menos protegida, el legislador no podrá afectar a derechos imprescindibles para la garantía de la dignidad humana, ni «al contenido delimitado para el derecho por la Constitución o los tratados internacionales suscritos por España» (F.J. 4). Igualmente establece con carácter general que

nales y no nacionales» $\mathrm{y}$ «(c)onsiderando que el apartado 1 del artículo 8 B del Tratado tiene por objeto que todos los ciudadanos de la Unión, tengan o no la nacionalidad de su Estado miembro de residencia, puedan ejercer en él en igualdad de condiciones su derecho de sufragio activo y pasivo en las elecciones municipales y que, en consecuencia, es necesario que dichas condiciones y, en particular, las relativas a la duración y prueba del período de residencia aplicables a los no nacionales, sean iguales que las aplicables, en su caso, a los nacionales del Estado miembro de que se trate; que los ciudadanos no nacionales no deben estar sujetos a condiciones específicas a menos que, excepcionalmente, pueda justificarse un trato diferente de los nacionales y de los no nacionales por circunstancias especiales que distingan a estos últimos de los primeros». 
«las condiciones de ejercicio que establezca respecto de los derechos y libertades de los extranjeros en España solo serán constitucionalmente válidas si, respetando su contenido esencial (art. 53.1 CE), se dirigen a preservar otros derechos, bienes o intereses constitucionalmente protegidos y guardan adecuada proporcionalidad con la finalidad perseguida.»

En el siguiente epígrafe aplicaremos las conclusiones aquí alcanzadas en un plano general al supuesto concreto del requisito de inscripción a instancia de parte en el censo electoral, que los tratados imponen a los extranjeros extracomunitarios.

\subsection{Análisis crítico del requisito de inscripción en el censo a instancia de parte}

En virtud de los tratados ratificados por España en la materia, es requisito indispensable para el ejercicio del derecho de sufragio activo la inscripción a instancia de parte en el censo electoral de extranjeros residentes en España. Esta instancia se presenta en el Ayuntamiento en cuyo padrón municipal el extranjero figure inscrito. Asimismo se dispone que el plazo de presentación se fije para cada proceso electoral ${ }^{82}$.

Este requisito de inscripción a instancia de parte en el censo electoral no parece corresponderse con el espíritu, ni posiblemente con la letra, de la LOREG. Esta, en su artículo 176.2 dispone que «(e)l Gobierno comunicará a la Oficina del Censo Electoral la relación de Estados extranjeros cuyos nacionales, residentes en España, deban ser inscritos en el Censo». La inscripción en el censo aparece aquí como obligatoria («deban ser inscritos»). Nada en la LOREG indica que tenga que ser a instancia de parte. Más bien, se trata de una excepción a la norma prevista en el artículo 32.2 LOREG, en virtud de la cual «(l)os Ayuntamientos tramitan de oficio la inscripción de los residentes en su término municipal». La fuente de la citada obligación se encuentra, pues, únicamente en los tratados, posteriormente desarrollados por normativa de rango reglamentario ${ }^{83}$. Ahora bien, en la medida en que los propios convenios prevén que España pueda, manteniendo el derecho, modificar las condiciones para su ejercicio allí previstas con un plazo de preaviso, nada nos impide cambiar la modalidad de

82 En el acuerdo con Noruega se añade que «(l)as listas electorales de ciudadanos noruegos residentes en España se elaborarán únicamente con ocasión de tales elecciones».

${ }^{83}$ Orden EHA/2264/2010, de 20 de julio, por la que se dictan normas e instrucciones técnicas para la formación del censo electoral de residentes en España que sean nacionales de países con Acuerdos para las elecciones municipales, modificada por la Orden ECC/1758/2014, de 23 de septiembre. 
inscripción en el censo electoral. Bastaría para ello por tanto con derogar y actualizar las disposiciones reglamentarias vigentes sobre la materia.

La inscripción a instancia de parte en el censo electoral no actúa propiamente como requisito para la adquisición del derecho, sino, tal y como se establece en los propios tratados, a modo de «requisito indispensable para el ejercicio del derecho de sufragio activo» ${ }^{84}$. Dicho en otros términos, posee un valor meramente declarativo, no constitutivo, del derecho. Sirve entonces para acreditar que se es titular del derecho. Dicha titularidad se adquiere en virtud de la entrada en vigor del tratado celebrado, lo que le otorga el derecho a figurar en el censo electoral, aunque procedimentalmente sea requerida para ello su solicitud ${ }^{85}$.

Esta exigencia produce, sin duda, un importante efecto disuasorio del ejercicio del derecho al voto por parte de los extranjeros residentes en nuestro país, que no ha pasado desapercibido en nuestra doctrina ${ }^{86}$.

En la medida en que, como hemos visto, es un rasgo de la ciudadanía la dispensación de un trato igual, se hace necesario examinar cuáles son los motivos que llevan a excluir a los extranjeros de la inscripción de oficio en el censo electoral, ya que de no existir estos o ser insuficientes se estaría incurriendo en discriminación. Por otra parte, en tanto que condición impuesta al ejercicio del derecho fundamental, su constitucionalidad está también sujeta al cumplimiento de determinados requisitos. Así, concretamente, su imposición debe justificarse en la necesidad de garantizar algún bien o derecho constitucionalmente reconocido; ha de respetar las exigencias derivadas del principio de proporciona-

84 En este mismo sentido, Moya, Regulación..., cit., p. 475.

85 En este punto sería aplicable la doctrina sentada en la STC 154/1988, que destaca «la conexión inescindible existente entre el derecho fundamental de sufragio y la inscripción censal, pues, dado que solo tendrán la condición de electores, y podrán ser elegibles, los ciudadanos que figuren inscritos en el censo (...), la inclusión en éste constituye un requisito indispensable para el ejercicio del derecho de sufragio. Es cierto que se trata de dos derechos de naturaleza distinta - la inscripción censal es de naturaleza declarativa de la titularidad del derecho de voto y no constitutiva de la misma-, pero no existe un derecho a tal inscripción separado del de sufragio, y éste comprende el de ser inscrito en el censo». Para el TC, «(d)ada la relevancia de la inscripción censal en el ejercicio del derecho fundamental de sufragio, el censo se convierte así en un instrumento indispensable para dicho ejercicio» (F.J. 3).

86 Así lo han visto Moya, op. cit., p. 475; Aja-Moya, op. cit., p. 21, Ortega Giménez, op. cit., pp. 33 y 37; CeBrián, J. A (2011). «Extranjería y Derecho de sufragio», Madrid, Fundación Ciudadanía y Valores, p. 9 (disponible en: http://digital.csic.es/bitstream/10261/50129/1/2011Extranjer\%C3\%Ada\%20Y\%20Derecho\%20De\%20Sufragio.pdf; Última Visita: 13/06/2017); Carrasco Durán, op. cit., p. 161. Para Ortega Giménez-López Álvarez-Cano Esquibel se trata de uno de los elementos que convierten el ejercicio del derecho en «misión imposible» (op. cit., p. 14). 
lidad y no afectar al contenido esencial del derecho ${ }^{87}$. Nos corresponde, pues, analizar los argumentos que se han venido esgrimiendo por la doctrina y las instituciones para su justificación.

En este sentido, se ha querido justificar el requisito de inscripción en el censo a instancia de parte en el objetivo de evitar la duplicidad del voto del residente extranjero ${ }^{88}$. Sin embargo, como señala el informe del Consejo de Estado, la proscripción del doble voto no se opone al hecho de que los extranjeros puedan mantener su derecho de sufragio en las elecciones municipales en ambos países, sino más bien «excluye que una misma persona pueda votar más de una vez en las mismas elecciones, lo que aquí, en rigor, no sucedería (se trataría del mismo tipo de elecciones, pero no de las mismas elecciones, por lo que no quedaría afectada la igualdad del voto)» ${ }^{89}$.

El propio órgano consultivo justificaba, sin embargo, en su informe la imposición de la citada condición en su coherencia con la exigencia de un período de residencia. Así, desde esta posición se argumenta que el hecho de que los efectos del voto se prolonguen durante el período de su mandato justifica el reconocimiento del derecho a quienes tienen una residencia habitual o con una vocación de permanencia, que quedaría plasmada en la manifestación de voluntad sobre su opción de ejercer el derecho en España ${ }^{90}$. Este argumento tampoco nos parece plausible. El significado otorgado por el Consejo de Estado a la solicitud de inscripción en el censo exigida a los extranjeros extracomunitarios está basado en ficciones difícilmente sostenibles en nuestro ordenamiento. En efecto, por un lado, dadas las características constitucionales del voto, la única manifestación posible de la voluntad de votar es el voto mismo. Más aún, dada la innegable connotación ideológica que subyace a la voluntad misma de votar, la exigencia de una previa declaración al respecto supone la imposición de una obligación que podría ser contraria al artículo 16.2 $\mathrm{CE}^{91}$. Por otro, nada permite deducir de dicha solicitud, ni mucho menos imponer, una suerte de compromiso de permanencia en el municipio en cuestión, por lo que su adecuación o utilidad respecto del fin supuestamente perseguido es del todo inexistente.

87 Para Santolaya Machetti, son «aceptables condiciones adicionales al tiempo de residencia siempre que superen un juicio de proporcionalidad y no sean, en sí mismas, discriminatorias» (Los Acuerdos..., cit., p. 22).

88 Así, Massó Garrote, op. cit., p. 143.

89 Informe del Consejo de Estado, op. cit., pp. 35-36.

90 Ibidem, p. 63. Justifica el requisito de inscripción en cada proceso electoral en el hecho de que «se entiende que se trata de un colectivo variable que, en cuatro años, puede haber cambiado de residencia o incluso haber abandonado el país», ORTEGa Giménez, op. cit., p. 31.

91 «Nadie podrá ser obligado a declarar sobre su ideología, religión o creencias». 
Asimismo, debe descartarse que la inscripción a instancia de parte en el censo electoral sea necesaria para acreditar la vinculación del extranjero con el ente territorial y, por ello, coherente con su condición de ciudadano. La vinculación al territorio determinante de la ciudadanía se encuentra ya suficientemente garantizada por un período previo de residencia en el territorio nacional y por el cumplimiento del requisito de vecindad. Exigir al ciudadano extranjero una vinculación reforzada en este modo respecto de la que es propia del nacional supone un exceso y queda así, únicamente, como un obstáculo injustificado añadido al ejercicio del voto por este ${ }^{92}$.

Ciertamente, la exigencia de una expresión previa de la voluntad de votar no es totalmente ajena a nuestro sistema electoral, ya que se pide a los ciudadanos comunitarios como condición de ejercicio del derecho al sufragio activo en las elecciones municipales. Sin embargo, la diferencia aquí sí está justificada. Cuando la Directiva comunitaria señala en sus considerandos que «conviene que dichos ciudadanos (los comunitarios residentes en un país del que no son nacionales) puedan expresar su voluntad de ejercer su derecho de voto» está buscando garantizar la libertad de los ciudadanos comunitarios «de participar o no en las elecciones municipales en el Estado miembro de residencia». Con ello se pretende dar salida a un posible conflicto entre el derecho al voto en las elecciones municipales del país de residencia y el mantenimiento del derecho de sufragio en el país del que es nacional, a la vista de que en cualquiera de ellos el voto puede resultar obligatorio. Esto es lo que explica que se añada entre los considerandos «que en los Estados miembros en los que no haya obligación de votar se permita de oficio el registro de esos ciudadanos».

Otro argumento vincula la inscripción a instancia de parte en las listas electorales de los extranjeros residentes en España al «carácter voluntario e individual de este ejercicio del derecho de sufragio por parte de extranjeros y su afirmación voluntaria con cada elección» ${ }^{93}$. El carácter voluntario e individual del voto es, sin embargo, parte del contenido del propio derecho, y no necesita de la

92 Como señala Presno Linera, «en democracia no cabe hablar de «ciudadanos pasivos», pues la ciudadanía presupone la posibilidad jurídica de decidir, de participar, con independencia de que, de hecho, se intervenga o no» (El voto de los extranjeros..., cit., p. 194).

93 Lozano García, J. L. (1991). Derecho de sufragio de los extranjeros en las elecciones locales. Memoria monográfica del curso selectivo de formación de secretarios de Embajada (1990-1991), Madrid, Escuela Diplomática, pp. 103 y 111. En contra, MAssó GARrote sostiene que «la inscripción en el censo electoral para nada tiene que ver con la voluntariedad o no en el ejercicio del derecho, pues la misma no va a quebrar por el hecho de que el extranjero sea inscrito de oficio por el Ayuntamiento y sea obligatoria en previsión del artículo 32.1 y 2 de la LOREG. Una vez inscrito en el censo electoral el extranjero podrá y no estará obligado a ejercer su derecho fundamental de sufragio» (op. cit., p. 143). 
supuesta garantía mencionada. Se acredita por el mero hecho de acudir a las urnas el día señalado para las elecciones. No existen motivos que justifiquen una prevención generalizada respecto de la existencia de manipulación o coacción en el ejercicio del derecho por el extranjero. Esta, de existir, deberá ser tratada por la misma vía penal prevista para esta conducta cuando el afectado es un español (vid. art. 146 LOREG). Tampoco se puede aceptar, en este sentido, la presunción de que el extranjero no vota en su condición de persona individual, sino en tanto que miembro de un colectivo determinado por su nacionalidad o, más en general, por su condición de no nacional. Más aún, aunque así fuera nada cabría oponer si a tal posición ideológica hubiera llegado libremente, pues algo parecido puede ocurrir con los propios nacionales.

Por último, tampoco parece que la norma persiga el objetivo de velar por la corrección de los datos del padrón, a partir de los que se elabora el censo. La LBRL prevé unos mecanismos que deben ser considerados suficientes en este sentido $^{94}$.

En definitiva, tanto la exigencia de instancia de parte para la inscripción en el censo electoral, como la de renovación de dicha solicitud con motivo de cada proceso resultan injustificadas e innecesarias para fin atendible alguno ${ }^{95}$. Esto hace que su imposición sea desproporcionada y dificulte su ejercicio «más allá de lo razonable» (STC 11/1981, F.J. 8), por lo que al tiempo que lesiona el derecho de sufragio activo de los extranjeros en las elecciones municipales, constituye una discriminación entre el ciudadano español y el extranjero en el ejercicio de tal derecho.

\section{CONCLUSIONES}

El alcance del reconocimiento del derecho al voto de los extranjeros en las elecciones municipales se ha visto decisivamente condicionado por una interpretación del artículo 13.2 CE que excluye toda posibilidad de atribución normativa del derecho a falta de concurrencia de reciprocidad. El resultado no puede

94 Véanse en este sentido especialmente los artículos 16.1, párrafos segundo y tercero, 17.2 y 17.3 del citado texto legal.

${ }^{9}$ Críticos con este requisito, Marín López, A. (1991). «Los derechos políticos de los extranjeros en España», Revista Española de Derecho Internacional, vol. XLIII, núm. 2, p. 362 y MAssó GARROTE, op. cit., pp. 146-147. Sostienen estos autores que la exigencia de solicitud expresa resulta innecesaria y se podría haber planteado en el momento de inscripción en el padrón, «puesto que si el Gobierno comunica a la Oficina del Censo Electoral la relación de Estados extranjeros cuyos nacionales, residentes en España, deben ser inscritos, no es necesaria una nueva solicitud para estar en las listas electorales» (ibídem, p. 147). 
ser calificado sino de decepcionante. La mayor parte de los extranjeros residentes legalmente en España se ven imposibilitados para ejercer el derecho, estableciéndose así un trato diferenciador en el colectivo, imposible de justificar desde la dogmática de los derechos fundamentales.

La reforma del precepto constitucional se presenta como la solución idónea. El objetivo deseable es la incorporación de una norma que atribuya directamente el derecho a todos los extranjeros, cualquiera sea su nacionalidad, y saque definitivamente esta cuestión del juego político. Este resultado no se logra con una mera supresión en el artículo 13.2 CE de la referencia a la reciprocidad, que seguiría dejando el reconocimiento del derecho en manos de la ley o del tratado internacional.

La interpretación del precepto constitucional actualmente aceptada no es, sin embargo, la única constitucionalmente posible. Del tenor literal del precepto se deduce que lo que se exige a la norma de atribución para ser conforme a la Constitución es que «atienda» a criterios de reciprocidad, esto es, que tome en consideración dicho elemento para la configuración de la solución normativa. Este requisito lo cumpliría una ley que reconociera con carácter general el derecho a los extranjeros, con la previsión de un plazo de residencia legal cuya mayor o menor duración se haría depender de la existencia efectiva de reciprocidad.

La sujeción al derecho a la igualdad del artículo 14 CE impediría al futuro texto legal excluir determinadas nacionalidades del reconocimiento del derecho. Tampoco estaría suficientemente justificada la imposición de restricciones a la eficacia de la norma basadas en el porcentaje de población extranjera residente en los municipios, siempre que la ley previera ya un período de residencia legal suficientemente amplio.

Por lo que respecta a Ceuta y Melilla, aunque los extranjeros tienen reconocido en la actualidad su derecho al voto en las elecciones a sus Asambleas, una eventual decisión del legislador de excluir estos procesos de la consideración de elecciones municipales no parece ir en contra de la Constitución. Antes bien, la especificidad del tratamiento constitucional de Ceuta y Melilla abre las puertas a la previsión de peculiaridades distintivas en su régimen jurídico respecto del general de los entes municipales. Este cambio debería ir, no obstante, precedido por una modificación de las normas estatutarias vigentes, que en la actualidad remiten la cuestión al régimen previsto por la LOREG para las elecciones locales.

Reconocido legalmente el derecho a los extranjeros, estos no pueden sino pasar a ser considerados ciudadanos a los efectos del artículo 23.1 CE, en virtud de una interpretación sistemática de este precepto con el inciso final del artículo 13.2 CE. Superado de este modo el binomio «nacional-extranjero», no se sostiene la concesión al legislador de un mayor margen de actuación en la impo- 
sición de condiciones para el ejercicio del derecho en el caso de los extranjeros. Cualquier medida en este sentido debe estar justificada objetiva y razonablemente y respetar las exigencias derivadas del principio de proporcionalidad. No ocurre esto con el requisito actualmente vigente de inscripción en el censo a instancia de parte, que debe ser considerado así contrario al texto constitucional.

\section{Title}

Municipal elections and the right to vote of non-EU foreigners: status of the question and reform proposals.

\section{Summary:}

1. Introduction. 2. The constitutional reciprocity clause. 2.1 Reciprocity as a requirement. 2.2 Towards a new interpretation of the constitutional clause. 3. The problem of the source of law. 3.1 The overcoming of the international treaty as a norm of attribution of the right. 3.2 On the possibility of limiting the scope of legal recognition of the right. 3.2.1 Exclusions on grounds of nationality. 3.2.2 The criterion based on the percentage of resident foreign population. 3.2.3 The particular cases of Ceuta and Melilla. 4. Conditions for the exercise of the right to vote of foreigners in municipal elections. 4.1 Limits to legislative action. 4.2 Critical analysis of the requirement of registration in the electoral census by personal application.

\section{Resumen:}

Este trabajo estudia el estado de la cuestión relativa al derecho al voto de los extranjeros no comunitarios en las elecciones municipales y sugiere nuevos enfoques en relación con las distintas vertientes del tema. Asimismo, propone y analiza los cambios normativos que podrían concretarse a raíz de esa nueva concepción. La cláusula constitucional de reciprocidad no obliga a excluir del derecho a los extranjeros procedentes de países que no cumplen el requisito, sino solo a tomar en consideración su concurrencia a la hora de definir su régimen normativo. Esta interpretación de la cláusula de reciprocidad abre las puertas a una atribución general del derecho fundamental mediante ley, lo que hace necesario estudiar la posible inclusión en ella de cláusulas que limiten su alcance. Finalmente se defiende que no se puede atribuir al legislador un margen de actuación más amplio al regular las condiciones de ejercicio del derecho cuando este es ejercido por un extranjero, lo que sirve para cuestionar la constitucionalidad de la exigencia de inscripción en el censo electoral a instancia de parte. 


\begin{abstract}
:
This paper studies the state of the issue regarding the right to vote of non-EU foreigners in municipal elections and suggests new approaches in relation to the different aspects of the issue. It also proposes and analyzes the normative changes that could materialize as a result of this new conception. The constitutional clause of reciprocity does not oblige to exclude from the right foreigners from countries that do not fulfill the requirement, but only to take into account its concurrence when defining their regulatory regime. This interpretation of the reciprocity clause opens the door to a general attribution of the fundamental right by law, which obliges to study the possible inclusion in it of clauses that limit its scope. Finally, it is argued that the legislator cannot be given a broader scope of action when regulating the conditions of exercise of the right when it is exercised by a foreigner, which serves to challenge the constitutionality of the requirement of registration in the electoral census by personal application.
\end{abstract}

\title{
Palabras clave:
}

Derecho al voto de los extranjeros, reciprocidad, ciudadanía, Ceuta y Melilla, censo electoral

Key words:

Foreigners' right to vote, reciprocity, citizenship, Ceuta y Melilla, electoral census. 